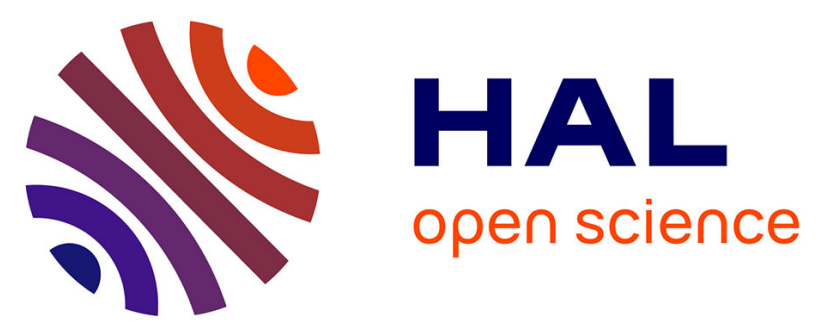

\title{
The interaction dynamics of a negative feedback loop regulates flagellar number in Salmonella enterica serovar Typhimurium.
}

Christine Aldridge, Kritchai Poonchareon, Supreet Saini, Thomas Ewen, Alexandra Solovyova, Christopher V. Rao, Katsumi Imada, Tohru Minamino, Phillip Aldridge

\section{To cite this version:}

Christine Aldridge, Kritchai Poonchareon, Supreet Saini, Thomas Ewen, Alexandra Solovyova, et al.. The interaction dynamics of a negative feedback loop regulates flagellar number in Salmonella enterica serovar Typhimurium.. Molecular Microbiology, 2010, 78 (6), pp.1416. 10.1111/j.13652958.2010.07415.x . hal-00585785

\section{HAL Id: hal-00585785 https://hal.science/hal-00585785}

Submitted on 14 Apr 2011

HAL is a multi-disciplinary open access archive for the deposit and dissemination of scientific research documents, whether they are published or not. The documents may come from teaching and research institutions in France or abroad, or from public or private research centers.
L'archive ouverte pluridisciplinaire HAL, est destinée au dépôt et à la diffusion de documents scientifiques de niveau recherche, publiés ou non, émanant des établissements d'enseignement et de recherche français ou étrangers, des laboratoires publics ou privés. 


\section{molecular microbiology}

\section{The interaction dynamics of a negative feedback loop regulates flagellar number in Salmonella enterica serovar Typhimurium.}

\begin{tabular}{|c|c|}
\hline Journal: & Molecular Microbiology \\
\hline Manuscript ID: & MMI-2010-10209.R1 \\
\hline Manuscript Type: & Research Article \\
\hline $\begin{array}{r}\text { Date Submitted by the } \\
\text { Author: }\end{array}$ & 08-Sep-2010 \\
\hline Complete List of Authors: & $\begin{array}{l}\text { Aldridge, Christine; Newcastle University, Centre for Bacterial Cell } \\
\text { Biology; Newcastle University, Institute for Cell and Molecular } \\
\text { Biosciences } \\
\text { Poonchareon, Kritchai; Newcastle University, Centre for Bacterial } \\
\text { Cell Biology; Newcastle University, Institute for Cell and Molecular } \\
\text { Biosciences } \\
\text { Saini, Supreet; University of Illinois at Urbana-Champaign, } \\
\text { Department of Chemical and Biomolecular Engineering } \\
\text { Ewen, Thomas; Newcastle University, Institute for Cell and } \\
\text { Molecular Biosciences } \\
\text { Solovyova, Alexandra; Newcastle University, Institute for Cell and } \\
\text { Molecular Biosciences } \\
\text { Rao, Christopher; University of Illinois, Dept. of Chemical and } \\
\text { Biomolecular Engineering } \\
\text { Imada, Katsumi; Osaka University, Department of Frontier } \\
\text { Biosciences } \\
\text { Minamino, Tohru; Osaka University, Graduate School of Frontier } \\
\text { Biosciences } \\
\text { Aldridge, Phillip; Newcastle University, Centre for Bacterial Cell } \\
\text { Biology; Newcastle University, Institute for Cell and Molecular } \\
\text { Biosciences }\end{array}$ \\
\hline Key Words: & Flagella, Protein:DNA interactions, Gene regulation \\
\hline
\end{tabular}

\section{SCHOLARONE ${ }^{\text {M }}$




\section{The interaction dynamics of a negative feedback loop}

\section{regulates flagellar number in Salmonella enterica serovar}

\section{Typhimurium.}

Christine Aldridge ${ }^{1,2}$, Kritchai Poonchareon ${ }^{1,2}$, Supreet Saini ${ }^{3}$, Thomas Ewen ${ }^{1,2}$, Alexandra Soloyva ${ }^{2}$, Christopher V. Rao ${ }^{3}$, Katsumi Imada ${ }^{4}$, Tohru Minamino ${ }^{4,5}$, and Phillip D. Aldridge $^{1,2^{*}}$

1: Centre for Bacterial Cell Biology, Medical Sciences New Building, Newcastle University, Richardson Road, Newcastle upon Tyne, United Kingdom, NE2 4AX. 2: Institute for Cell and Molecular Biosciences, Newcastle University, Framlington Place, Newcastle upon Tyne, United Kingdom, NE2 4HH. 3: Department of Chemical and Biomolecular Engineering, University of Illinois at Urbana-Champaign, Urbana, Illinois, United States, 61801. 4: Graduate School of Frontier Biosciences, Osaka University, 1-3 Yamadaoka, Suita, Osaka 565-0871, Japan. 5: PRESTO, JST, 4-1-8 Honcho, Kawaguchi, Saitama 332-0012, Japan.

* Corresponding Author: Email: p.d.aldridge@ncl.ac.uk; Tel: +44-191-208-3218; Fax +44191-208-3205 


\section{Summary}

Each Salmonella enterica serovar Typhimurium cell produces a discrete number of complete flagella. Flagellar assembly responds to changes in growth rates through $\mathrm{FlhD}_{4} \mathrm{C}_{2}$ activity. FlhD ${ }_{4} \mathrm{C}_{2}$ activity is negatively regulated by the type 3 secretion chaperone FliT. FliT is known to interact with the flagellar filament cap protein FliD as well as components of the flagellar type 3 secretion apparatus. FliD is proposed to act as an antiregulator, in a manner similar to FlgM inhibition of $\sigma^{28}$ activity. We have found that efficient growth-dependent regulation of $\mathrm{FlhD}_{4} \mathrm{C}_{2}$ requires FliT regulation. In turn, FliD regulation of FliT modulates the response. We also show that, unlike other flagellar-specific regulatory circuits, deletion of fliT or fliD did not lead to an all-or-nothing response in $\mathrm{FlhD}_{4} \mathrm{C}_{2}$ activity. To investigate why, we characterized the biochemical interactions in the FliT:FliD:FlhD ${ }_{4} \mathrm{C}_{2}$ circuit. When $\mathrm{FlhD}_{4} \mathrm{C}_{2}$ was not bound to DNA, FliT disrupted the $\mathrm{FlhD}_{4} \mathrm{C}_{2}$ complex. Interestingly, when $\mathrm{FlhD}_{4} \mathrm{C}_{2}$ was bound to DNA it was insensitive to FliT regulation. This suggests that the FliT circuit regulates $\mathrm{FlhD}_{4} \mathrm{C}_{2}$ activity by preventing the formation of the $\mathrm{FlhD}_{4} \mathrm{C}_{2}$ :DNA complex. Our data would suggest that this level of endogenous regulation of $\mathrm{FlhD}_{4} \mathrm{C}_{2}$ activity allows the flagellar system to efficiently respond to external signals. 


\section{Introduction}

Salmonella enterica serovar Typhimurium utilizes flagella, self-assembled nanomachines anchored in the cell envelope, to swim through liquids and swarm over surfaces. Approximately 60 flagellar genes, organized into 13 operons, are involved in flagellar assembly, motility and chemotaxis. The expression of the flagellar genes follows a strict hierarchy resulting in the subdivision of the flagellar operons into three classes based on the promoters that drive their transcription: $P_{\text {class } 1,} P_{\text {class2 }}$ and $P_{\text {class } 3}$ (Chilcott and Hughes, 2000). There is only one $P_{\text {class } 1}$ promoter that drives transcription of the genes flhD and flhC. FlhD and FlhC form a hetero-hexameric complex, $\mathrm{FlhD}_{4} \mathrm{C}_{2}$, which is the master regulator of the enteric flagellar systems (Wang et al., 2006). $\mathrm{FlhD}_{4} \mathrm{C}_{2}$ activates transcription itself through a direct interaction with the alpha subunit of RNA polymerase, allowing $\sigma^{70}$ to activate transcription from $\mathrm{FlhD}_{4} \mathrm{C}_{2}$ specific promoters (Liu et al., 1995). Previous studies of the $\mathrm{FlhD}_{4} \mathrm{C}_{2}$ have shown that the DNA binding component is primarily directed through FlhC. FlhD has been proposed to stabilize the $\mathrm{FlhD}_{4} \mathrm{C}_{2}$ :DNA complex (Claret and Hughes, 2000). There are eight $\mathrm{FlhD}_{4} \mathrm{C}_{2}$-dependent flagellar-specific $\mathrm{P}_{\text {class2 }}$ promoters. One of these promoters drives the transcription of the fliA gene, encoding an alternative sigma factor, $\sigma^{28}$, required for transcription from the eight $P_{\text {class } 3}$ promoters (Ohnishi et al., 1990). The gene products of $f l h D, f l h C$ and fliA are essential for the expression of the flagellar genes.

Along with fliA, a further regulatory component transcribed from both $\mathrm{P}_{\text {class2 }}$ and $\mathrm{P}_{\text {class3 }}$ promoters is $f / g M$. The gene product of $f(g M$ is an anti-sigma factor that directly interacts with $\sigma^{28}$ in the cell, preventing $\sigma^{28}$ from activating transcription from the $P_{\text {class } 3}$ promoters during HBB assembly (Gillen and Hughes, 1991a; Gillen and Hughes, 1991b). Upon HBB completion $P_{\text {class3 }}$ activation is coupled to flagellar assembly through the 
physical secretion of FlgM via the flagellum, thus freeing $\sigma^{28}$ to activate transcription from $P_{\text {class3 }}$ promoters (Hughes et al., 1993; Kutsukake and lino, 1994).

The coupling of assembly and gene expression suggests that some gene products are only expressed at a given stage of the assembly pathway. However, one limitation of this model is that it only considers a single flagellum. S. enterica does not produce a single flagellum per cell. Rather, it produces many, approximately four to eight per cell (lino, 1974). Thus, in a growing cell with more than one flagellum, all components required to assemble a complete flagellum are in theory present. Therefore, the flagellar system likely requires additional levels control in the presence of growing or assembled flagella that allow it to coordinate and adjust flagellar gene expression accordingly. Specifically, the presence of an upper limit in flagella number suggests that a negative feedback loop, sensitive to the number of flagella present, exists to modulate the activity of the regulators $\mathrm{FlhD}_{4} \mathrm{C}_{2}$ and $\sigma^{28}$.

For $\sigma^{28}$ :FlgM, the physical secretion of FlgM itself through completed HBB structures provides a given level of control for $\sigma^{28}$. We have recently shown that changing the rate of FlgM secretion modulates $\sigma^{28}$ activity (Brown et al., 2008). Ideally, a level of negative feedback similar to the $\sigma^{28}$ :FlgM circuit would regulate the activity of the master regulator FlhD ${ }_{4} \mathrm{C}_{2}$ in response to flagellar assembly. As $\mathrm{FlhD}_{4} \mathrm{C}_{2}$ is at the top of the transcriptional hierarchy, any changes in its activity will have the net affect of reducing both $\mathrm{P}_{\text {class } 2}$ activity

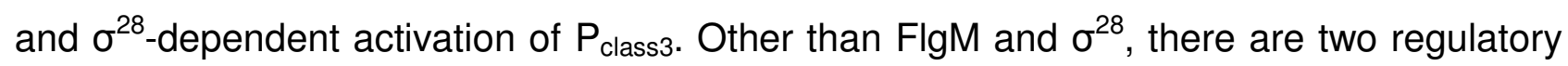
proteins that modulate flagellar gene transcription: FliT and FliZ (Kutsukake et al., 1999; Saini et al., 2008; Yamamoto and Kutsukake, 2006). The necessary negative feedback required to regulate $\mathrm{FlhD}_{4} \mathrm{C}_{2}$ activity to secretion is the anti-FlhD $\mathrm{C}_{2}$ factor, FliT (Yamamoto and Kutsukake, 2006). FliT is known to inhibit $\mathrm{FlhD}_{4} \mathrm{C}_{2}$-binding to DNA 
through its direct interaction with FlhC (Yamamoto and Kutsukake, 2006), while it also interacts with the filament-capping protein FliD and two soluble proteins, Flil and FliJ, of the flagellar T3S apparatus (Evans et al., 2006; Fraser et al., 1999; Imada et al., 2010). FliJ enhances FliT/FliD interactions with the C-terminal cytoplasmic domain of FlhA, a key protein of the flagellar-specific type III secretion apparatus (Bange et al.; Saijo-Hamano et al.). The interactions of FliT with FliD, FlhA and FliJ are thought to facilitate the secretion of FliD upon completion of the HBB. With respect to its interaction with FlhC, FliT has been defined as an anti-FlhD $\mathrm{C}_{2}$ factor and FliD an anti-anti-FlhD ${ }_{4} \mathrm{C}_{2}$ factor (Yamamoto and Kutsukake, 2006). In this regulatory circuit, $\mathrm{FlhD}_{4} \mathrm{C}_{2}$ would regulate flagellar assembly in response to the rate of FliD secretion.

FliT consists of four $\alpha$-helices ( $\alpha 1, \alpha 2, \alpha 3$, and $\alpha 4$ ) (Imada et al., 2010). A truncation of the C-terminal a4-helix, leading to FliT94, increases the binding affinity for the $\mathrm{FlhD}_{4} \mathrm{C}_{2}$ complex, suggesting that a4 plays an autoregulatory role in modulating FliT activity. A surface exposed residue Lys-79 in $\alpha 3$ is critical for the interaction with FliD. The $\alpha 4$ helix binds to the hydrophobic cleft formed by $\alpha 2$ and $\alpha 3$. As a truncation of $\alpha 4$ does not affect the interaction with FliD or $\mathrm{FlhD}_{4} \mathrm{C}_{2}$ per se, it is proposed that the interaction between $\alpha 4$ and the hydrophobic cleft modulates the binding affinity for the $\mathrm{FlhD}_{4} \mathrm{C}_{2}$ complex (Imada et al., 2010).

In this work, we investigate the role of FliT regulation of $\mathrm{FlhD}_{4} \mathrm{C}_{2}$ during continual flagellar assembly. We show that FliT regulation of $\mathrm{FlhD}_{4} \mathrm{C}_{2}$ activity allows the system to efficiently respond to bacterial growth rates. In addition, unlike the all-or-nothing response observed with respect to the deletion of $f l i A\left(\sigma^{28}\right)$ or $f l g M$, genetic analysis of the FliT circuit suggests FliT tunes the activity of the $\mathrm{FlhD}_{4} \mathrm{C}_{2}$, but never switches it off. To investigate the mechanism behind this behavior, we performed a biochemical characterization of the 
FliT:FliD:FlhD ${ }_{4} \mathrm{C}_{2}$ circuit. Using this approach, we show that FliT regulates $\mathrm{FlhD}_{4} \mathrm{C}_{2}{ }^{-}$ dependent activation of $\mathrm{P}_{\text {class2 } 2}$ by disrupting the $\mathrm{FlhD}_{4} \mathrm{C}_{2}$ complex. However, FliTdependent inhibition is unable to disrupt the $\mathrm{FlhD}_{4} \mathrm{C}_{2}$-DNA complex. Based on our results, we propose the model that FliT regulation of $\mathrm{FlhD}_{4} \mathrm{C}_{2}$ allows the flagellar system to respond efficiently to external regulatory inputs directed through changes in $F \mid h D_{4} C_{2}$ activity. 


\section{Results}

\section{The assembly of flagella in S. enterica responds to changes in growth rates.}

Recently a two-fold change in flhDC gene expression was shown to increase flagellar numbers by two-fold (Erhardt and Hughes). This study used, in part, a chromosomally encoded, functional FliM-GFP fusion to numerate flagella by the number of HBB per cell (Aldridge et al., 2006a). A significant number of studies over the past 5 decades monitor $S$. enterica flagellar assembly in LB. We asked if the growth conditions were changed, would a similar flagella distribution or a growth dependent phenotype be observed. Using the FliM-GFP construct we counted the number of HBB per cell of $S$. enterica grown in four conditions. We used a minimal medium base (Minimal E plus $0.2 \%$ Glucose) containing increasing amounts of Yeast Extract (YE) $(0.04 \mathrm{~g} / \mathrm{L}, 0.2 \mathrm{~g} / \mathrm{L}, 1 \mathrm{~g} / \mathrm{L}$ and $3 \mathrm{~g} / \mathrm{L})$. Yeast extract was chosen, as it could increase growth rates to that equivalent of LB (3 g/L YE (data not shown). Growth was performed at $30^{\circ} \mathrm{C}$ for consistency with previous experiments performed (Brown et al., 2008). The rationale of adding rich nutrients to a base medium was similar to seminal growth experiments performed by Schaechter et al., to observe changes in growth mass in S. enterica at different growth rates (Schaechter et al., 1958).

Flagellar numbers were counted at late exponential phase of standard shaken cultures prior to the transition into stationary phase (Figure 1A, Figure S1 and Table 1). This time point is suggested to coincide with maximal flagellar gene expression (Pruss and Matsumura, 1996; Pruss and Matsumura, 1997). We observed an unexpected growth dependent phenotype that went against our perception of flagella utilisation. In our nutrient limiting conditions $(0.04 \mathrm{~g} / \mathrm{L} \mathrm{YE})$ we observed a significant reduction in flagellar numbers compared to $3 \mathrm{~g} / \mathrm{L}$ YE. Changing carbon source or using a defined amino acid mix did not 
alter this response (data not shown). On average, growth in $0.04 \mathrm{~g} / \mathrm{L}$ YE produced 0.3 flagella/cell, while $3 \mathrm{~g} / \mathrm{L}$ YE produce 3.74 flagella/cell (Table 1). No cells were observed for $0.04 \mathrm{~g} / \mathrm{L} \mathrm{YE}$ with more than 2 foci (Figure $1 \mathrm{~A}$ ). In contrast to growth in $0.04 \mathrm{~g} / \mathrm{L}$ that exhibited an exponential distribution of flagellar numbers, $3 \mathrm{~g} / \mathrm{L}$ YE growth produced a Gaussian (or normal) distribution of flagellar numbers. For the $3 \mathrm{~g} / \mathrm{L}$ YE population, $90 \%$ of cells observed possessed one or more foci (Table 1). This suggests that only when nutrients are perceived will flagellar numbers increase, dependent on nutrient availability, to achieve optimal swimming behavior and therefore chemotaxis. These observations are consistent with previous reports on the influence of media composition on the flagellation of $E$. coli (Adler and Templeton, 1967).

\section{FliT regulation is required to allow the system to respond accurately to external signals}

The response of the $S$. enterica flagellar system to growth conditions suggests the system is flexible enough to respond to external cues, even though motility is defined as a robust phenotype (Barkai and Leibler, 1997). The majority of external signals are transduced into the flagellar system through changes in flhDC expression or $\mathrm{FlhD}_{4} \mathrm{C}_{2}$ stability, observable as a change in $\mathrm{FlhD}_{4} \mathrm{C}_{2}$ activity (Soutourina and Bertin, 2003). Yamamoto and Kutsukake (2006) have shown that $F \mathrm{IhD}_{4} \mathrm{C}_{2}$ activity is negatively regulated via a direct interaction with FliT. This suggests that $\mathrm{FlhD}_{4} \mathrm{C}_{2}$ activity is regulated by internal signals from the flagellar system. In their work, it was proposed that FliD regulates the ability of FliT to inhibit FlhD ${ }_{4} \mathrm{C}_{2}$ activity (Yamamoto and Kutsukake, 2006). Therefore, FliT regulation of FlhD $\mathrm{C}_{2}$ activity sensitises the system to flagellar assembly via FliD secretion rates (Brown et al., 2008). As a growth dependent phenotype for flagella numbers was observed, we asked which level of regulation was dominant, the external regulation of $\mathrm{FlhD}_{4} \mathrm{C}_{2}$ or the 
endogenous regulation through FliT. We therefore compared FliM-GFP foci numbers in our growth conditions for $\Delta f l i T$ and $\Delta$ fliD mutants to wild type (Figure 1B and C).

We observed a significant increase in flagellar numbers at all growth rates for the $\Delta f l i T$ mutant compared to wild type (Figure 1B and Figure S1). The percentage of cells with foci also significantly increased for the $\Delta$ fliT mutant compared to wild type. Grown in $0.04 \mathrm{~g} / \mathrm{L}$ YE $60 \%$ of cells from the $\Delta f l i T$ mutant population contained FliM-GFP foci as compared to $24 \%$ in wild type. The average number of FliM-GFP foci in the $\Delta f l i T$ mutant also increased in all conditions (Table 1). Consistently, a reciprocal drop in flagellar numbers was observed for the $\Delta$ fliD mutant (Figure 1C, Figure S1, and Table 1). Even for $3 \mathrm{~g} / \mathrm{L}$ YE the $54 \%$ of foci containing cells of the $\Delta f l i D$ mutant had only one or two foci $(16 / 50$ cells) with only a small proportion having 3 foci ( 4 cells), 4 foci ( 3 cells), 5 foci ( 2 cells) or 6 foci (2 cells) (Figure 1C). Importantly, the $\Delta$ fliT and $\Delta$ fliD phenotypes were observed at all growth rates, suggesting that the level of regulation exerted through FliT on $\mathrm{FlhD}_{4} \mathrm{C}_{2}$ is independent of growth. Furthermore the data suggests that for the system to respond to external cues efficiently, endogenous regulation of $\mathrm{FlhD}_{4} \mathrm{C}_{2}$ by FliT is required.

\section{Overexpression of fliT does not halt flagellar gene expression completely.}

Consistent with the flagellar numbers of the $\Delta$ fliT and $\Delta$ fliD mutants, plasmid-based expression of fliT or fliD resulted in the expected change. An increase of full-length fliT concentration by approximately 4 fold (data not shown) was unable to completely inhibit movement as assayed using motility agar plates (Figure 2A). This level of increased fliT expression resulted in only $2 \%$ of cells possessing one FliM-GFP foci in comparison to 90 $\%$ in wild type. The recent description of the FliT structure suggested that a C-terminal ahelix modulates FliT activity (Imada et al., 2010). Deletion of this $\alpha$-helix, producing the 
variant fliT94, resulted in a further reduction in motility on motility agar after 8 hours incubation when fliT94 was expressed from a high copy number plasmid (pSE-fliT94) or as a GST fusion protein (pGST-fliT94 (pMMT002) - Figure 2A) (Imada et al., 2010). In comparison, overexpression of either flgM or fliA from pSE380 did not reduce motility in soft agar plates significantly (Figure 2A). This suggests that the $\sigma^{28}$ :FlgM and FliT regulatory circuits play distinct roles in regulating flagellar assembly, albeit that they are interlinked by $\sigma^{28}$-dependent transcription of the fliDST operon.

We have recently established a flagellar gene expression assay that monitors flagellar gene expression through a Fla to $\mathrm{Fla}^{+}$transition (Brown et al., 2008). The motility phenotypes of plasmid-based expression of fliT and fliT94 suggest that a basal level of flagellar gene expression is still present. To confirm this, flagellar gene expression dynamics were measured for plasmid-based fliT or fliT94 expression from pSE380 (Figure 2B). As compared to wild type, plasmid-based expression of fliT and fliT94 resulted in a significant delay in activation of $\mathrm{P}_{\text {class2 }}$ and $\mathrm{P}_{\text {class3 }}$ promoters. However, the flagellar transcriptional hierarchy was still evident in all strains (Figure 2B). When expressing fliT, $\mathrm{P}_{\text {flgA }}$ activity peaked at $1672 \mathrm{RLU}$ at 91 minutes, a 4.9 fold reduction compared to its vector control that peaked at 8219 at 119 minutes. For fliT94 $\mathrm{P}_{f l g A}$ activity reached a maximum activity of 1067 RLU at 98 minutes, a 7.7 fold reduction in activity. For the $P_{\text {class } 3}$ promoter

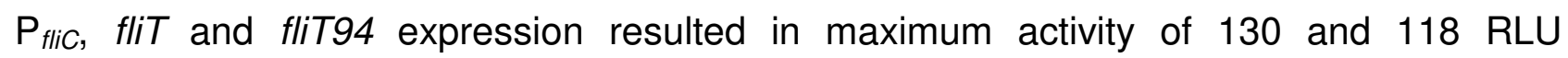
respectively compared to $15339 \mathrm{RLU}$ for the vector control. These observations are consistent with the proposed function of $\alpha 4$ modulating FliT activity by binding into a cleft formed by helices $\alpha 2$ and $\alpha 3$. Importantly, both constructs were unable to completely inhibit flagellar gene expression. Instead, flagellar gene expression is significantly reduced to a basal level that can still sustain some motility. Therefore, this suggests that for the 
observed phenotypes, some aspect of the FliT: $\mathrm{FlhD}_{4} \mathrm{C}_{2}$ regulatory circuit prevents FliT completely inhibiting $\mathrm{FlhD}_{4} \mathrm{C}_{2}$ from activating flagellar gene expression.

\section{FliT disrupts the free $\mathrm{FIhD}_{4} \mathrm{C}_{2}$ complex}

The in vivo data on FliT regulation suggests that even in excess, FliT is unable to completely inhibit $\mathrm{FlhD}_{4} \mathrm{C}_{2}$. Instead, the data suggests that FliT acts to significantly reduce FlhD ${ }_{4} \mathrm{C}_{2}$ activity. However, the in vivo data does not offer an explanation to how this level of regulation by FliT is achieved or why it exists. We therefore investigated the biochemical characteristics of the FliT regulatory circuit in vitro to determine if the nature of the interactions between FliT, FliD, $\mathrm{FlhD}_{4} \mathrm{C}_{2}$ and the $\mathrm{FlhD}_{4} \mathrm{C}_{2}$ DNA binding site could aid our understanding of FliT regulation in vivo.

Yamamoto and Kutsukake (2006) were able to show that FliT interacts with FlhC of the $\mathrm{FlhD}_{4} \mathrm{C}_{2}$ complex. All in vitro analysis in this work focussed on FliT regulation of the FlhD ${ }_{4} \mathrm{C}_{2}$ complex rather than FlhC itself. The rationale for this approach argued that to understand the in vivo data, how the $\mathrm{FlhD}_{4} \mathrm{C}_{2}$ complex behaves in the presence of FliT rather than FIhC alone was important. We began by asking whether we could isolate an FlhD ${ }_{4} \mathrm{C}_{2}$ :FliT complex. FlhD ${ }_{4} \mathrm{C}_{2}$ and FliT were purified separately, mixed at different molar ratios and subjected to gel filtration. No high molecular weight species characteristic of a stable FliT:FlhD $\mathrm{C}_{2}$ complex was observed (data not shown). The analyses of the FliT: $\mathrm{FlhD}_{4} \mathrm{C}_{2}$ interaction using surface plasma resonance (SPR) and isothermal calorimetry were unable to add any value to understanding the gel filtration data. We therefore utilised analytical ultra-centrifugation (AUC) to characterise the FliT:FlhD ${ }_{4} \mathrm{C}_{2}$ interaction further (Figure 3). 
FliT exists in equilibrium between its monomeric and dimeric form in solution, as judged by sedimentation equilibrium AUC measurements (Imada et al., 2010). Analysis of $\mathrm{FlhD}_{4} \mathrm{C}_{2}$, by sedimentation velocity $\mathrm{AUC}$, produced a single protein species with a mass of 94.9 kDa. This is in good agreement with the theoretical mass of the $\mathrm{FlhD}_{4} \mathrm{C}_{2}$ complex (96.7 kDa) (Wang et al., 2006). Addition of FliT to $\mathrm{FlhD}_{4} \mathrm{C}_{2}$ at a $1: 1$ molar ratio using $8 \mu \mathrm{M}$ $\mathrm{FlhD}_{4} \mathrm{C}_{2}$ did not produce a high molecular weight species larger than $94.9 \mathrm{kDa}$. Instead the $\mathrm{FlhD}_{4} \mathrm{C}_{2}$ peak was reduced in size and a long shoulder that tapered towards the left of the $\mathrm{FlhD}_{4} \mathrm{C}_{2}$ peak appeared. Higher ratios of $\mathrm{FliT}: \mathrm{FlhD}_{4} \mathrm{C}_{2}$ were then analysed and resulted in the shoulder becoming a defined peak with a predicted mass of $61-63 \mathrm{kDa}$. According to the size of this new protein species we assume that it could either be the dissociated $\mathrm{FlhD}_{4}$ tetramer or a FliT:FlhC 2 complex. This data suggests that on interaction of FliT with $\mathrm{FlhD}_{4} \mathrm{C}_{2}$, the net result is the disassociation of the $\mathrm{FlhD}_{4} \mathrm{C}_{2}$ complex through the interaction of FliT with FlhC. This is in agreement with a previous report that the amount of FlhD coeluted with GST-FliT94 from a GST column is much lower than that of FlhC (Imada et al., 2010).

\section{Inhibition of $\mathrm{FIhD}_{4} \mathrm{C}_{2}$ :DNA complex formation requires excess FliT}

Within the FliT regulatory circuit, the key interaction is $F \mathrm{IhD}_{4} \mathrm{C}_{2}$-binding to its DNA binding site. Based on our AUC results, we speculated that excess amounts of FliT would provide increased inhibition of $\mathrm{FlhD}_{4} \mathrm{C}_{2}$ :DNA binding. To test our hypothesis, we chose a SPR approach. We immobilized 350-400 RU of double stranded 80-mers, biotinylated on one strand, to a streptavidin sensor chip containing the $\mathrm{FlhD}_{4} \mathrm{C}_{2}$ DNA binding site from flgB $\left(\mathrm{P}_{f l g B}\right)$ and $f l h B\left(\mathrm{P}_{f l h B}\right)$ and an intergenic region of fliC coding sequence as a control DNA. Consecutive injections of $\mathrm{FlhD}_{4} \mathrm{C}_{2}$ in a dilution series to $\mathrm{P}_{f l g B}$ DNA exhibited a concentration dependent response (Figure 4A). Addition of FliT in a $1: 1$ ratio with $\mathrm{FlhD}_{4} \mathrm{C}_{2}$ prior to 
injection resulted in a significant reduction in $\mathrm{FlhD}_{4} \mathrm{C}_{2}$ :DNA interaction but did not completely inhibit it (Figure 4A). Analysis of the data showed that $V_{\max }$ for $F \mathrm{Fh}_{4} \mathrm{C}_{2}$ alone to be 3933 compared to 560 for $\mathrm{FlhD}_{4} \mathrm{C}_{2}$ and FliT (Table S2). Binding to $\mathrm{P}_{\text {flhB }}$ and fliC DNA (data not shown) showed consistency with previous studies on the $\mathrm{FlhD}_{4} \mathrm{C}_{2}$ :DNA interaction. Stafford et al. showed that $\mathrm{FlhD}_{4} \mathrm{C}_{2}$ could bind to DNA without a defined FlhD ${ }_{4} \mathrm{C}_{2}$ binding site (Stafford et al., 2005; Wang et al., 2006). Therefore, the observation that $\mathrm{FlhD}_{4} \mathrm{C}_{2}$ bound to a coding region of fliC is not that surprising.

Our AUC data suggested that increasing molar ratios of FliT:FlhD $\mathrm{C}_{2}$ would significantly disrupt the $\mathrm{FlhD}_{4} \mathrm{C}_{2}$ complex. Using our SPR assay the ability of increasing FlhD ${ }_{4} \mathrm{C}_{2}$ :FliT ratios to inhibit $\mathrm{FlhD}_{4} \mathrm{C}_{2}$ to bind its $\mathrm{DNA}$ binding site were tested. Increasing amounts of FliT were added to $100 \mathrm{nM} \mathrm{FlhD}{ }_{4} \mathrm{C}_{2}$ giving the ratios of $1: 1,1: 1.5,1: 2.5$ and 1:4 prior to injection over $\mathrm{P}_{f \mid g B}$ (Figure 4B). Increasing amounts of FliT significantly reduced the ability of $\mathrm{FlhD}_{4} \mathrm{C}_{2}$ to bind to its binding site (Table S2). Molar ratios higher than $1: 4$ gave similar results (data not shown) suggesting that the maximal level of inhibition in our assays of the $\mathrm{FlhD}_{4} \mathrm{C}_{2}$ to DNA interaction is a ratio of approximately $1: 4$.

\section{A FlhD ${ }_{4} \mathrm{C}_{2}$ :DNA complex is resistant to FliT regulation}

The above observations from our AUC and initial SPR analysis are sufficient to explain the observed phenotypes of the $\Delta f l i T$ and $\Delta f l i D$ mutants and fliT overexpression with respect to FliM-GFP foci. Our data suggests that to completely inhibit $\mathrm{FlhD}_{4} \mathrm{C}_{2}$ a high ratio of FliT to FlhD ${ }_{4} \mathrm{C}_{2}$ is required. Previous studies characterising the $\mathrm{FlhD}_{4} \mathrm{C}_{2}$ :DNA interaction have established that the $\mathrm{FlhD}_{4} \mathrm{C}_{2}$ :DNA complex is very stable with a half-life of approximately 40 minutes (Claret and Hughes, 2000). Thus, irrespective of the level of free FliT, its regulation of $\mathrm{FlhD}_{4} \mathrm{C}_{2}$ will potentially encounter $\mathrm{FlhD}_{4} \mathrm{C}_{2}$ bound to $\mathrm{DNA}$. Therefore we 
asked what effect would FliT have upon an $\mathrm{FlhD}_{4} \mathrm{C}_{2}$ :DNA complex using our SPR assay (Figure 5). The injection of PBS running buffer did not show any effect, as expected. Unexpectantly, FliT would not disrupt the already existing $\mathrm{FlhD}_{4} \mathrm{C}_{2}: \mathrm{DNA}$ complex (Figure $5 \mathrm{~A}$ - addition of a $100 \mathrm{nM}$ solution of FliT to bound $\mathrm{FlhD}_{4} \mathrm{C}_{2}$ complexes is shown). In these assays a constant concentration of $100 \mathrm{nM} \mathrm{FlhD}{ }_{4} \mathrm{C}_{2}$ was first bound to the immobilised DNA. Even a 100-fold excess of FliT $(10 \mu \mathrm{M})$ could not disrupt the $\mathrm{FlhD}_{4} \mathrm{C}_{2}$ :DNA complex (data not shown). In contrast and as a control to show that $\mathrm{FlhD}_{4} \mathrm{C}_{2}$ was bound and could be disassociated, injecting $100 \mathrm{nM}$ free $\mathrm{P}_{\text {flgB }}$ DNA resulted in disassociation of the $\mathrm{FlhD}_{4} \mathrm{C}_{2}$ :DNA complex from all 3 DNA species tested (Figure 5B). Importantly, this control also showed that the interaction dynamics of $\mathrm{FlhD}_{4} \mathrm{C}_{2}$ with the three DNA species behaved in agreement with a previous work (Stafford et al., 2005). These results, therefore, suggest that FliT can prevent $\mathrm{FlhD}_{4} \mathrm{C}_{2}$ from binding DNA but if $\mathrm{FlhD}_{4} \mathrm{C}_{2}$ is already bound to DNA, $\mathrm{FlhD}_{4} \mathrm{C}_{2}$ is resistant to $\mathrm{FliT}$ regulation.

\section{FliD acts as an anti-anti-FlhD $\mathrm{C}_{2}$ factor}

The phenotype of a $\Delta f l i D$ mutant with respect to changes in flagellar gene expression and that FliD directly interacts with FliT led Yamamoto and Kutsukake (2006) to propose that FliD acts as an anti-anti-FlhD ${ }_{4} \mathrm{C}_{2}$ factor. However, this hypothesis has not been experimentally explored. We therefore used the SPR-based assay of $\mathrm{FlhD}_{4} \mathrm{C}_{2}$ binding DNA to observe what effect FliD would have upon FliT inhibition of $\mathrm{FlhD}_{4} \mathrm{C}_{2}$.

As FliD:FliT interact in a $1: 1$ molar ratio, a $1: 1: 1$ ratio of FliD:FliT:FlhD ${ }_{4} \mathrm{C}_{2}$ was assayed. Addition of FliD to $\mathrm{FlhD}_{4} \mathrm{C}_{2}$, in the absence of FliT, did not alter the ability of FlhD ${ }_{4} \mathrm{C}_{2}$ to bind DNA (Figure 6). This was in agreement with gel filtration and bacterial twohybrid analysis that did not identify a FliD:FlhD ${ }_{4} \mathrm{C}_{2}$ interaction (data not shown). In 
contrast, a mix of FliD, FliT and $\mathrm{FlhD} \mathrm{D}_{4} \mathrm{C}_{2}$ did alter the ability of FliT to inhibit $\mathrm{FlhD}_{4} \mathrm{C}_{2}$ from binding DNA (Figure 6). A similar response to the addition of FliD to a $1: 1 \mathrm{mix}$ of FliT94: $\mathrm{FlhD}_{4} \mathrm{C}_{2}$ was also observed (Figure S2). Therefore we can confirm Yamamoto and Kutsukake's proposal that FliD does act in an anti-anti-FlhD ${ }_{4} \mathrm{C}_{2}$ manner. Interestingly, a complete inhibition of FliT regulation was not observed.

\section{The FliD/FlhD $\mathrm{C}_{2}$ binding sites on FliT overlap}

The data above suggests that FliD interaction with FliT when all proteins are at a 1:1:1 ratio is not sufficient to completely inhibit the regulation of $\mathrm{FlhD}_{4} \mathrm{C}_{2}$ by FliT. One explanation for this is that the binding sites for FliD and $\mathrm{FlhD}_{4} \mathrm{C}_{2}$ are on distinct surfaces of FliT. As a result even in the presence of FliD, FliT could disrupt the $\mathrm{FlhD}_{4} \mathrm{C}_{2}$ complex. An alternative explanation is that the sites of interaction overlap and the observed response is due to $\mathrm{FliD} / \mathrm{FlhD}_{4} \mathrm{C}_{2}$ competition for FliT. To distinguish between these two models, a genetic analysis of fliT was performed. Our intent was to determine if fliT point mutations would exist that could bind FliD but not interact with $\mathrm{FlhD}_{4} \mathrm{C}_{2}$ and vice versa. The $\mathrm{P}_{\text {class } 1}$ flhDC promoter is negatively autoregulated by $\mathrm{FlhD}_{4} \mathrm{C}_{2}$ (Figure 7). Deletion of fliT although observed to have increased $P_{\text {class2 }}$ activity, exhibits reduced $P_{\text {class1 }}$ activity (Figure 7). This suggests that FliT regulation effects not only $\mathrm{P}_{\text {class2 }}$ activity but also $\mathrm{FlhD}_{4} \mathrm{C}_{2}$ levels through regulation of the autoregulatory control of the $\mathrm{P}_{\text {class } 1}$ promoter region by $\mathrm{FlhD}_{4} \mathrm{C}_{2}$. Our screen used the drop in $\mathrm{P}_{\text {class } 1}$ activity associated with loss of FliT regulation to isolate fliT mutations exhibiting reduced activity against $\mathrm{FlhD}_{4} \mathrm{C}_{2}$. Mutations in fliT were isolated using random PCR mutagenesis (Aldridge et al., 2006b). From 2000 colonies, 17 colonies with reduced $P_{\text {class } 1}$ activity were isolated randomly and sequenced. From these 9 had single point mutations, 3 had two point mutations, 2 had triple mutations, one had a C-terminal extension of 25 amino acids due to the mutation of the stop codon and one did not contain 
any mutation in the coding sequence of fliT (data not shown). Using the recently described structure of FliT the single point mutations were found to all cluster in $\alpha 1$ or $\alpha 3$. Interestingly, one mutation N74D was at the same residue as had been identified to show weaker FliD interaction (Imada et al., 2010). This suggests that the FliD and $\mathrm{FlhD}_{4} \mathrm{C}_{2}$ binding sites on FliT may in fact overlap.

To further investigate whether the $\mathrm{FliD} / \mathrm{FlhD}_{4} \mathrm{C}_{2}$ binding sites on FliT overlap, we assayed alanine substitution mutants in the C-terminal portion of $\alpha 3$ in motility assays, an FlhC pull-down assay (Imada et al., 2010) and the SPR-based assay. Motility assays of these mutations introduced into fliT94 showed that five exhibited a strong reduction in the ability of fliT94 to inhibit motility: 168A, N74A, E75A, K79A and L82A (Figure 8A). Consistently, in a pull-down assay one of these mutations (E75A) showed a significant drop in its ability to interact with FlhC compared to those that showed a similar phenotype to wild type fliT94 (Figure 8B).

Four substitutions showing motility were also assayed for their ability to inhibit the $\mathrm{FlhD}_{4} \mathrm{C}_{2}$ :DNA interaction. In agreement with the motility and pull-down assays FliT94(E75A) exhibited the weakest inhibition of the DNA interaction (Figure 8C and Table S2). In contrast, the substitutions K79A and L82A behaved in a similar fashion showing inhibition at ratios greater than 1:2 of $\mathrm{FlhD}_{4} \mathrm{C}_{2}: \mathrm{FliT94}$, while N74A exhibited a slight drop in inhibition at all concentrations. Importantly, all alanine substitutions still retained the ability to bind to FlhC to some extent and therefore inhibited wild-type motility (Figure 8). Therefore, these mutants strongly suggest that the $\mathrm{FliD} / \mathrm{FlhD}_{4} \mathrm{C}_{2}$ interface on FliT somehow overlap and the observed response in the SPR analysis is the result of competition for FliT. 


\section{Discussion}

A key factor often overlooked with respect to flagellar assembly is how the cell coordinates the synthesis of multiple flagella during bacterial growth. Here we have presented evidence suggesting that enteric bacteria are able to sense the extent of their flagellation via an endogenous regulatory circuit that modulates the activity of $\mathrm{FlhD}_{4} \mathrm{C}_{2}$. Furthermore this internal regulation is key to allow the system to respond accurately to extracellular environmental, internal metabolic or growth dependent signals.

Two key observations from this study showed that i) loss of $\mathrm{FlhD}_{4} \mathrm{C}_{2}$ regulation by FliT disrupted an efficient response to changes in growth conditions and ii) if bound to DNA, $\mathrm{FlhD}_{4} \mathrm{C}_{2}$ was insensitive to $\mathrm{FliT}$ regulation. Consistent with both observations was the finding that deleting fliD or expressing full length or a truncated fliT variant from a plasmid was unable to completely inhibit $\mathrm{FlhD}_{4} \mathrm{C}_{2}$ activity in any growth condition. That when bound to DNA, FlhD ${ }_{4} \mathrm{C}_{2}$ was insensitive to FliT regulation is an intriguing twist to an already complex regulatory network that couples flagellar gene expression to the assembly pathway.

Hughes and co-workers predicted that FlhC was the major DNA binding component of the $\mathrm{FlhD}_{4} \mathrm{C}_{2}$ complex (Claret and Hughes, 2000). Yamamoto and Kutsukake (2006) when describing the FliT:FlhD ${ }_{4} \mathrm{C}_{2}$ interaction were able to show that FliT was interacting with FlhC. Our data are in agreement with these observations. The resistance of the $\mathrm{FlhD}_{4} \mathrm{C}_{2}$ :DNA complex to FliT suggests that the FliT binding site on FlhC overlaps the FlhC DNA binding domain. This is different than the model presented by Wang et al., (2006) when $\mathrm{FlhD}_{4} \mathrm{C}_{2}$ was crystallised. Wang et al., (2006) proposed a configuration that shows FlhD being the major DNA binding component. However, when discussing this model, they 
conceded that the data available were insufficient to rule out other plausibility's, such as FlhC making the majority of the DNA:protein contacts (Wang et al., 2006). Our data, with that of the co-workers of Hughes and Kutsukake suggests that the proposed alternative is more feasible but still requires direct biochemical or structural evidence to confirm the correct orientation.

Our genetic analysis of the FliT: $\mathrm{FlhD}_{4} \mathrm{C}_{2}$ interaction suggests that it is not only the interaction sites of FliT and DNA on FlhC that overlap. Mutations in FliT itself, previously shown to reduce FliD interaction, were also found to have reduced activity in inhibiting $\mathrm{FlhD}_{4} \mathrm{C}_{2}$ (Imada et al., 2010). A conclusion based on the analysis of alanine substitutions in the truncated variant FliT94. The genetic analysis, in conjunction with our biochemical analysis, suggests that a key factor in the way that FliT regulates $\mathrm{FlhD}_{4} \mathrm{C}_{2}$ is the extent of competition between all components. As a result this circuit is sensitive to the availability of FliT to bind FliD, FliT to bind FlhC and the availability of $\mathrm{FlhD}_{4} \mathrm{C}_{2}$ to bind DNA. A swing in the balance between these three reactions will alter the level of $F / h D_{4} C_{2}$ output in terms of transcription activation.

In agreement with previous data we have shown that $F \mathrm{hD}_{4} \mathrm{C}_{2}$ can bind DNA unspecifically (Stafford et al., 2005). The mode of binding may be different, as seen during the competition assays using unbiotinylated $\mathrm{P}_{\text {flgB }} \mathrm{DNA}$ to disassociate the $\mathrm{FlhD}_{4} \mathrm{C}_{2}: \mathrm{DNA}$ complexes (Figure 5B). The ability of $\mathrm{FlhD}_{4} \mathrm{C}_{2}$ to bind DNA even without a defined binding site could potentially have an impact of FliT regulation as it means $\mathrm{FlhD}_{4} \mathrm{C}_{2}$ does not only have to bind to its specific sites to become resistant to FliT.

What is the advantage of $F / h D_{4} C_{2}$ being regulated by FliT only when not bound to DNA? A recent study using SPR, which our assays were based on, showed that the 
RelBE system behaves somewhat different to $\mathrm{FlhD}_{4} \mathrm{C}_{2}$ regulation by FliT. The RelBE system is an toxin-antitoxin locus in which the toxin component can cleave mRNA associated with ribosomes but also autoregulates the transcription of the relBE locus (Overgaard et al., 2008). If RelE interacts with a RelB:DNA complex the result is disassociation of the proteins from the DNA (Overgaard et al., 2008). The flagellar and RelBE systems are very different with respect to their regulation. For the flagellar system there is an advantage for a given basal level of activity to exist even when flhDC expression is under significant negative influence from the long list of regulators that can influence its expression (Soutourina and Bertin, 2003). Both a $P_{\text {class2 }}$ and a $P_{\text {class3 }}$ promoter drive the transcription of fliT. Thus, even at low levels of $f l h D C$ expression some FliT can be made, even if no complete HBBs are present. The apparent competition between all components that our data suggests, predicts that even during HBB assembly, when FliD is not being secreted, a given level of FliT would be available to interact with free $\mathrm{FlhD}_{4} \mathrm{C}_{2}$. Note also that activation of FlgM secretion allows $\sigma^{28}$ to increase transcription of fliT. Therefore once one structure is complete the level of free FliT will increase due to changes in FliD and FlgM levels as a result of secretion. We propose the working model that under growth conditions that exhibit significant inhibition of flhDC expression, FliT regulation will control the extent of flagellation by further inhibiting any free $\mathrm{FlhD}_{4} \mathrm{C}_{2}$ found in the cell. However, if the $F / h D_{4} C_{2}: D N A$ interaction occurs first then bound $\mathrm{FlhD}_{4} \mathrm{C}_{2}$ will be insensitive to FliT regulation.

Our data suggests that under certain environmental conditions a basal level of FlhD ${ }_{4} \mathrm{C}_{2}$ activity is maintained via a balance between external regulation of flhDC expression and internal regulation through, for example, FliT inhibition of $\mathrm{FlhD}_{4} \mathrm{C}_{2}$. The result is that a small proportion of cells amongst the population will possess a low number of flagella. It is then the subpopulation of flagellated cells that are able to begin to move 
out of the current location to seek more preferential growth conditions. Adler and Templeton (1967) drew similar conclusions from their work to gain maximum motility of $E$. coli in a defined chemical medium. Interestingly, how efficient chemotaxis would be in $E$. coli or S. enterica cells possessing low flagella numbers has not been explored in detail and in the light of this work would be an interesting line of investigation (Darnton et al., 2007; Turner et al., 2000).

Thus, in conclusion we have shown that the enteric flagellar system requires a given level of endogenous negative feedback regulation to respond to external signals. For enteric bacteria this regulation is via the negative regulation of $\mathrm{FlhD}_{4} \mathrm{C}_{2}$ activity by FliT. We further conclude that FliT is unable to completely inhibit $\mathrm{FlhD}_{4} \mathrm{C}_{2}$ from activating flagellar gene expression, thus preparing the population to respond, with respect to the flagellar system, accordingly to external signals. What is now of interest is to begin to question how non- $\mathrm{FlhD}_{4} \mathrm{C}_{2}$ dependent systems control the same response. 


\section{Materials and Methods}

Bacterial Strains, Plasmids and Cultivation

Strains and Plasmids used during this study are described in Table 2. Media used in this study included LB broth and Minimal E (Davis et al., 1980; Vogel and Bonner, 1956). All plates contained $1.5 \%$ agar. Motility assays were performed using semi-solid motility agar containing $0.3 \%$ difco agar. Cultures were grown at either $37^{\circ} \mathrm{C}$ or $30^{\circ} \mathrm{C}$ with constant shaking at $180 \mathrm{rpm}$. Antibiotic concentrations have been described previously (Bonifield et al., 2000). For the growth condition experiment Minimal E base salts were supplemented with $0.2 \%$ glucose and the stated concentration of Yeast extract from a stock solution of $25 \mathrm{~g} / \mathrm{L}$. For purification of FliT, FliD and $\mathrm{FlhD}_{4} \mathrm{C}_{2} \mathrm{LB}$ cultures were grown to an OD600 nm between 0.4 and 0.6 at $37^{\circ} \mathrm{C}$. Induction of expression for 3 to 5 hours was achieved using a final concentration of $1 \mathrm{mM} \mathrm{IPTG}$ with incubation at $30^{\circ} \mathrm{C}$. Cell pellets were harvested and stored at $-80^{\circ} \mathrm{C}$ until needed.

\section{DNA Manipulation}

Throughout this study standard cloning and DNA manipulation techniques have been used. All plasmids were sequenced prior to use. Primer sequences used for constructs are available on request. A modified version of pET28a-mod was used in this study that reduced the size of the his-tag fused to FliT or FliD with a region of the multiple cloning site deleted (Table 2). For the purification of $\mathrm{FlhD}_{4} \mathrm{C}_{2}$ the entire flhDC operon was subcloned into pET28a-mod. On induction this produced a complex that was his- $\mathrm{FlhD}_{4} \mathrm{C}_{2}$. All protein identities were also confirmed by MALDI-TOF analysis using an in-house facility at Newcastle (PINNACLE). 
Random mutagenesis of fliT was performed using the natural error rate of Taq DNA polymerase. A PCR reaction generated using Taq DNA polymerase was recombined onto the chromosome of strain TPA993 selecting on Tetracycline-sensitive $\left(\right.$ Tet $\left.^{\mathrm{S}}\right)$ plates (Aldridge et al., 2006b). After selection, crossing once more on to $\mathrm{Tet}^{\mathrm{S}}$ plates was used to isolate 2000 colonies. A pool of the 2000 colonies was then transduced with plasmid pRG38 ( $\left.\mathrm{P}_{\text {flhDC: }}: / \mathrm{l} X A B C D E\right)$ to screen for potential fliT mutants. To isolate colonies exhibiting reduced light production, images of the transduction plates were made using the chemiluminescent settings of an intelligent light box. Seventeen colonies were taken at random and purified to isolate phage free colonies before light production was confirmed using liquid cultures assayed in a BMG Fluostar microplate reader. The fliT-coding region was then sequenced from PCR products. Deletion of fliD in TPA2421 used previously described recombineering protocols (Aldridge et al., 2003; Datsenko and Wanner, 2000).

\section{Epifluorescent Microscopy}

To visualise FliM-GFP, cultures were grown as described above. At appropriate time points or OD600 nm values, one microlitre of culture was spotted onto a $1 \%$ agarose pad containing 1 x E-salts but no glucose in a Gene frame ( $A B$ gene). The agarose pad was sealed with a coverslip, a procedure sufficient to immobilize the motile bacteria. Images were acquired on a Zeiss Axiovert 200M system (Murray and Errington, 2008). An exposure time for all GFP images of 1.5 seconds was used and 100 milliseconds for a phase contrast image. Images were captured through METAMORPH (version V.6.2r6) and then processed using ImageJ $(\mathrm{NIH})$.

To count FliM-GFP foci all cells were counted using the dot function of ImageJ. From the counted cells a random number generator (www.randomizer.org) was used to identify 50 cells from each time point and strain. Using a stacked RGB composite image of 
the GFP and phase contrast images, the FliM-GFP foci were then counted manually in the identified cells. Histograms of the number distributions and statistical analysis were performed using Excel (Microsoft).

\section{Protein Purification}

All protein isolations were done using an Akta Prime Plus (GE Healthcare). Purification of FliT and FliD was performed using standard purification protocols. Briefly, cell pellets of induced cultures were resuspended in His-loading buffer: $50 \mathrm{mM}$ HEPES, $150 \mathrm{mM} \mathrm{NaCl}$, $20 \mathrm{mM}$ Imidazole, $\mathrm{pH} 7.5$ and sonicated for $5 \mathrm{~min}$ on ice. To remove all cell debris the sample was centrifuged at $31,500 \times \mathrm{g}$ for $30 \mathrm{~min}$ at $4^{\circ} \mathrm{C}$ prior to injection over a preequilibrated $5 \mathrm{ml}$ his-trap column (GE Healthcare). Proteins were eluted using an $80 \%$ Imidazole gradient over $50 \mathrm{ml}$ of His-elute buffer: $50 \mathrm{mM}$ HEPES, $150 \mathrm{mM} \mathrm{NaCl}, 1 \mathrm{M}$ Imidazole, $\mathrm{pH} 7.5$.

FlhD ${ }_{4} \mathrm{C}_{2}$ purification was performed using a modified method described by Wang et al., (2006). Plasmid pPA158 was freshly transformed into BL21 and induced cell pellets isolated from up to 6 litres of culture and resuspended in Buffer A: $20 \mathrm{mM}$ Tris, pH 7.9. The cell suspension was sonicated for $5 \mathrm{~min}$, centrifuged for $30 \mathrm{~min}$ at $31,500 \times \mathrm{g}$ at $4^{\circ} \mathrm{C}$ and injected over a $5 \mathrm{ml}$ Heparin column (GE Healthcare). After injection, the column was washed with a $20 \%$ solution of Buffer B: $20 \mathrm{mM}$ Tris, $1 \mathrm{M} \mathrm{NaCl}$, pH 7.9. After the baseline reached a pre-loading level, elution of the $\mathrm{FlhD}_{4} \mathrm{C}_{2}$ complex was achieved using a gradient of Buffer B up to $100 \%$ applied over 60 minutes. All protein fractions were checked by SDS page on $16.5 \%$ Tricine gels.

After purification FliT, FliD and $\mathrm{FlhD}_{4} \mathrm{C}_{2}$ proteins were concentrated using VIVAspin columns (10 kDa cutoff) and subjected to gel filtration using a S200 column (GE 
Healthcare). The gel filtration buffer used was $20 \mathrm{mM}$ Tris, $300 \mathrm{mM} \mathrm{NaCl}, 1 \mathrm{mM}$ DTT, pH 7.9. Pull down assays by GST affinity chromatography have been previously described (Imada et al., 2010).

\section{Surface Plasma Resonance}

The majority of SPR experiments were performed using the BIAcore 2000. Experiments using FliT94 were performed on a Bio-Rad Proteon XPR36. DNA-protein interaction experiments were done using a streptavidin (SA) or neutravidin coated sensor chips (GE Healthcare and Bio-Rad). The running buffer for all experiments was phosphate buffered saline (PBS). For the DNA-protein experiments using the BIAcore 2000365 resonance units $(R U)$ of DNA were immobilized on the SA sensor chip, while for the XPR36 $100 \mathrm{RU}$ were immobilized. Prior to immobilization, 3 consecutive injections over all flow cells for 60 seconds at a flow rate of $10 \mu \mathrm{l} /$ min with $1 \mathrm{M} \mathrm{NaCl}$ then $0.05 \mathrm{M} \mathrm{NaOH}$ were performed to ensure no contamination of unspecific bound compounds. An empty flowcell was always used as a negative control for background subtraction and therefore had no DNA or protein bound to it. The DNA used was an 80 bp double-stranded oligonucleotide, with a 5 'biotinylated forward strand of the $f / g B$ and $f l h B$ binding sites of $\mathrm{FlhD}_{4} \mathrm{C}_{2}$ (Table 3) (Stafford et al., 2005). Also as a negative control we used an intergenic region of fliC (Table 3). Annealing of the DNA was performed using a Biometra T3000 Thermocycler: $94^{\circ} \mathrm{C}$ for 2 min then ramp cooled to $25^{\circ} \mathrm{C}$ over 45 min then kept at $4^{\circ} \mathrm{C}$ until use. Annealing of samples was confirmed by native gel electrophoresis on $10 \%$ native gels. For all experiments $\mathrm{FlhD}_{4} \mathrm{C}_{2}$ protein was applied for 60 seconds over all four flow cells. Regeneration of the flow cells was done using a 10 second injection of $6 \mathrm{M}$ guanidine$\mathrm{HCL}$. As a control for chip quality $\mathrm{FlhD}_{4} \mathrm{C}_{2}$ alone was always run at the beginning, middle and end of an experimental set. For protein-protein interactions standard BIAcore 
protocols were followed using $300 \mathrm{RU}$ of FliT immobilized on a CM5 sensor chip as ligand and either FliD or $\mathrm{FlhD}_{4} \mathrm{C}_{2}$ as analyte.

\section{Analytical Ultracentrifugation}

Sedimentation velocity (SV) experiments were carried out in a ProteomeLab XL-I analytical ultracentrifuge (Beckman Coulter, USA) using both absorbance (at $280 \mathrm{~nm}$ ) and interference optics. All AUC runs were carried out at a rotation speed of $48,000 \mathrm{rpm}$ and an experimental temperature of $4^{\circ} \mathrm{C}$ using an 8-hole rotor and double-sector aluminiumepon centrepieces. The sample volume was $400 \mu$ for the SV experiments with sample concentrations between 0.2 and $1.2 \mathrm{mg} / \mathrm{ml}$. The partial specific volumes $(\overline{\mathrm{v}})$ for the proteins were calculated from the protein amino acid sequence, using the program SEDNTERP and extrapolated to the experimental temperature. The density and viscosity of the buffer (10 mM Tris pH 7.5, $1 \mathrm{mM}$ EDTA, $200 \mathrm{mM} \mathrm{NaCl}$ ) at the experimental temperature was also calculated using SEDNTERP.

The distributions of sedimenting material were modelled as a distribution of Lamm equation solutions where the measured sedimentation boundary was modelled as an integral over differential concentration distributions $\mathrm{c}(\mathrm{s})$ as implemented in the program SEDFIT (http://www.analyticalultracentrifugation.com) (Schuck, 1998). The sedimentation velocity profiles were fitted using a maximum entropy regularisation parameter of $p=0.95$. The weight average sedimentation coefficient was calculated by integrating the differential sedimentation coefficient distribution (Schuck, 2003). Sedimentation coefficients (s) were extrapolated to zero concentration and converted to standard conditions, i.e. those that would be measured at $20^{\circ} \mathrm{C}$ in water. The diffusion coefficient (D) corresponding to each sedimentation coefficient value was estimated from a weight-average frictional ratio $\left(f / f_{0}\right)_{\mathrm{w}}$ 
(Schuck, 1998; Schuck, 2003). Conversion to a molecular mass distribution from S and D was made using the Svedberg equation

$$
\mathrm{M}=\frac{\mathrm{sRT}}{\mathrm{D}(1-\overline{\mathrm{v}} \rho)}
$$

where $R$ is gas constant, $T$ is temperature, $\bar{v}$ is a partial specific volume of solute and $\rho$ is density of the buffer. The integration of the mass distribution $\mathrm{c}(\mathrm{M})$ was made similarly to the integration of $\mathrm{c}(\mathrm{s})$ distribution in order to determine the weight average molecular mass of each species. 


\section{Acknowledgements}

We would like to thank all lab members and colleagues for critical reading of this manuscript. Special thanks goes to W. Vollmer for his input. We would also like to thank R. Daniel, H. Murray and J. Errington for use of their microscope suite and M. KinoshitaMinamino for technical assistance. Thanks also go to Bob Lightowlers for access and advice on the use of the BIAcore 2000. BBSRC Grant No. BB/D015855/1 awarded to P.A. funded the majority of this work. K.P was awarded a PhD scholarship from Nareasuan University (Thailand). C.R. was partially supported by the National Science Foundation Grant CBET 0644744 and by Public Health Service Grants GM083601 and GM054365. Funding for K.I. and T.M is through the Targeted Proteins Research Program from the Ministry of Education, Science and Culture of Japan (K.I and T.M). An International Project Grant awarded jointly by the Diawa Foundation and Royal Society (UK) funded T.M. and P.A. 
Table 1: Statistics of the FliM-GFP foci distribution in wild type. $\Delta$ fliT and $\Delta f l i D$

\begin{tabular}{|c|c|c|c|c|c|}
\hline $\begin{array}{l}\text { Condition } \\
\text { (YE g/L) }\end{array}$ & Strain & $\begin{array}{l}\text { Growth } \\
\text { rate - } \mu^{\star}\end{array}$ & $\begin{array}{l}\text { Doubling } \\
\text { time } \\
(\min )^{\star}\end{array}$ & $\begin{array}{l}\text { Percentage of } \\
\text { cells with FliM- } \\
\text { GFP foci }\end{array}$ & $\begin{array}{c}\text { Average } \\
\text { number of } \\
\text { FliM-GFP } \\
\text { foci }\end{array}$ \\
\hline \multirow{3}{*}{0.04} & Wild Type & 0.0084 & 82.30 & 24 & $0.30 \pm 0.58$ \\
\hline & $\Delta f l i T$ & 0.0083 & 83.35 & 60 & $1.28 \pm 1.59$ \\
\hline & $\Delta f l i D$ & 0.0083 & 83.70 & 16 & $0.22 \pm 0.55$ \\
\hline \multirow{3}{*}{0.2} & Wild Type & 0.0089 & 77.52 & 38 & $0.50 \pm 0.81$ \\
\hline & $\Delta f l i T$ & 0.0089 & 77.57 & 62 & $2.88 \pm 3.88$ \\
\hline & $\Delta f l i D$ & 0.0088 & 79.02 & 26 & $0.30 \pm 0.54$ \\
\hline \multirow{3}{*}{1} & Wild Type & 0.0124 & 55.89 & 58 & $1.91 \pm 2.26$ \\
\hline & $\Delta f l i T$ & 0.0119 & 58.30 & 96 & $5.46 \pm 2.72$ \\
\hline & $\Delta f l i D$ & 0.0119 & 58.47 & 18 & $0.22 \pm 0.51$ \\
\hline \multirow{3}{*}{3} & Wild Type & 0.0138 & 50.16 & 90 & $3.74 \pm 2.41$ \\
\hline & $\Delta$ fliT & 0.0135 & 51.30 & 92 & $5.32 \pm 3.27$ \\
\hline & $\Delta f l i D$ & 0.0133 & 52.01 & 54 & $1.40 \pm 1.74$ \\
\hline
\end{tabular}

${ }^{*}$ Calculated from 3 independent growth cultures. Standard deviations can be found in Table S1 
Table 2: Strains and Plasmids used in this study

\begin{tabular}{|c|c|c|c|}
\hline $\begin{array}{c}\text { Strain } \\
\text { No. }\end{array}$ & $\begin{array}{c}\text { Strain/plasmid } \\
\text { name }\end{array}$ & Genotype & Reference \\
\hline $\begin{array}{l}\text { TPA14 } \\
\text { TPA20 } \\
\text { TPA993 } \\
\text { TPA1107 } \\
\text { TPA2390 } \\
\text { TPA2421 }\end{array}$ & $\begin{array}{l}\text { LT2 } \\
\text { BL21 } \\
\text { DH5a } \\
\\
\text { Wild type* } \\
\Delta f l i T^{*} \\
\Delta f l i D^{\star}\end{array}$ & $\begin{array}{l}\text { Wild type strain } \\
\mathrm{F}^{-} \text {ompT hsdSB dcm gal } \lambda(\mathrm{DE} 3) \\
\text { phi-80d lacsm15 enda1 recA1 hsdR17 } \\
\text { supE44 thh-1 gyrA96 relA } \Delta / a c U 169 \\
\mathrm{P}_{\text {flhDc5451::Tn10[del-25] }} \\
\text { fliT::Km } \\
\Delta \text { fliT7046::tetRA } \\
\text { fliM5978-gfp (Mot+) } \\
\text { fliM5978-gfp fliT::Km } \\
\text { fliM5978-gfp } \Delta \text { fliD7097::FRT }\end{array}$ & $\begin{array}{l}\text { K. Hughes } \\
\text { Promega } \\
\text { New England Biolabs } \\
\text { (Karlinsey et al., 2000) } \\
\text { (Kutsukake et al., 1999) } \\
\text { (Aldridge et al., 2006a) }\end{array}$ \\
\hline & $\begin{array}{l}\text { pET28a-mod } \\
\text { pGEX6p-1 } \\
\text { pMMT002 } \\
\text { pMMT002(I68I) } \\
\text { pMMT002(L72A) } \\
\text { pMMT002(N74A) } \\
\text { pMMT002(E75A) } \\
\text { pMMT002(K79A) } \\
\text { pMMT002(L81A) } \\
\text { pMMT002(L82A) } \\
\text { pMMT002(Q83A) } \\
\text { pPA152 } \\
\text { pPA158 } \\
\text { pPA159 } \\
\text { pRG38 } \\
\text { pRG39::cat } \\
\text { pRG52::cat } \\
\text { pSE380 } \\
\text { pSE-fliT } \\
\text { pSE-fliT94 } \\
\text { pSE-flgM } \\
\text { pSE-fliA }\end{array}$ & $\begin{array}{l}\text { His-tag plasmid } \\
\text { GST expression plasmid } \\
\text { fliT94 in pGEX6p-1 (pGEX-fliT(2-94)) } \\
\text { fliT94(I68A) in pGEX6p-1 } \\
\text { fliT94(L72A) in pGEX6p-1 } \\
\text { fliT94(N74A) in pGEX6p-1 } \\
\text { fliT94(E75A) in pGEX6p-1 } \\
\text { fliT94(K79A) in pGEX6p-1 } \\
\text { fliT94(L81A) in pGEX6p-1 } \\
\text { fliT94(L82A) in pGEX6p-1 } \\
\text { fliT94(Q83A) in pGEX6p-1 } \\
\text { fliT in pET28a-mod } \\
\text { flhDC in pET28a-mod } \\
\text { fliD in pET28a-mod } \\
P_{\text {flhDC in pSB401 }} \\
P_{\text {flic in pSB401 }} \\
P_{\text {flgB }} \text { in pSB401 } \\
\text { fliT in pSE380 } \\
\text { fliT94 in pSE380 } \\
\text { flgM in pSE380 } \\
\text { fliA in pSE380 }\end{array}$ & $\begin{array}{l}\text { Novagen } \\
\text { Stratagene } \\
\text { (Imada et al., 2010) } \\
\text { (Imada et al., 2010) } \\
\text { (Imada et al., 2010) } \\
\text { (Imada et al., 2010) } \\
\text { (Imada et al., 2010) } \\
\text { (Imada et al., 2010) } \\
\text { (Imada et al., 2010) } \\
\text { (Imada et al., 2010) } \\
\text { (Imada et al., 2010) } \\
\\
\text { (Goodier and Ahmer, } \\
\text { 2001) } \\
\text { (Brown et al., 2008) } \\
\text { (Brown et al., 2008) } \\
\text { Invitrogen }\end{array}$ \\
\hline
\end{tabular}

* Names used in conjunction with Figure 1 and Table 1. 
Table 3: DNA Sequences used for SPR analysis.

\section{Name Sequence ${ }^{\S}$}

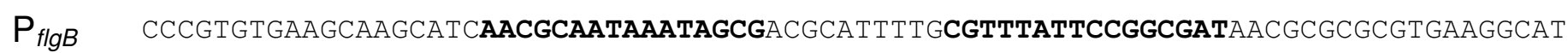

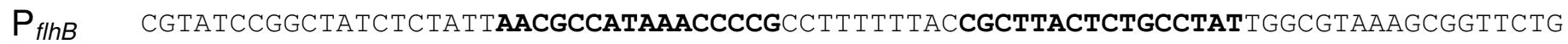

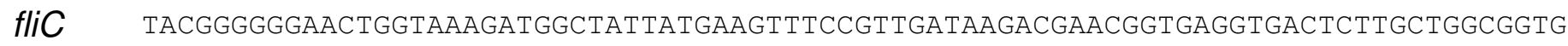

$\S$ The FlhD ${ }_{4} \mathrm{C}_{2}$ inverted repeat as defined by Stafford et al., (2005) is shown in bold. 


\section{Figure Legends}

Figure 1: Effect of growth conditions on the distribution of FliM-GFP foci in wild type (A), $\Delta f l i T$ (B) and $\Delta$ fliD (C) strains. Growth conditions are described in the text and Materials and Methods. Black: MinE + 0.04 g/L YE; Gray: MinE + 0.2 g/L YE; Hashed: MinE + 1 g/L YE and White: MinE $+3 \mathrm{~g} / \mathrm{L}$ YE. FliM-GFP foci were observed at 270 minutes after dilution, a time point defined as late log phase. The data shown is one data set of each strain grown at $30^{\circ} \mathrm{C}$ for 270 minutes where $n=50$ cells for each strain in each condition were counted. The results have been confirmed by a minimum of 3 independent repeats.

Figure 2: Plasmid-based expression of FliT and FliT94 is unable to halt flagellar gene expression. (A) Motility assays of pSE380, pSE-fliT, pSE-fliT94 and pGST-fliT94 in comparison to pSE-flgM and pSE-fliA in LT2 after $8 \mathrm{hrs}$ at $30^{\circ} \mathrm{C}$. (B) Temporal gene expression assay comparing a vector control (triangles), pSE-fliT (circles) and pSE-fliT94 (diamonds). The activities of the promoters $P_{f f g A}\left(P_{\text {class2 }}\right)$ (black line, solid symbols) and $P_{f i C}$ ( $\left.P_{\text {class3 }}\right)$ (grey lines, open symbols) are shown. Plasmid-based expression is able to delay activation of both promoter classes but activity and hierarchical expression is still observed. A stronger delay for $\mathrm{P}_{\text {flgA }}$ is observed for pSE-fliT94, consistent with the regulatory role of $a 4$ to modulate FliT activity. For clarity the $\mathrm{P}_{\text {flic }}$ activity for pSE-fliT and pSE-fliT94 are plotted on the second $\mathrm{Y}$-axis. This level of $\mathrm{P}_{\text {flic }}$ activity is still sufficient to sustain a low level of motility as seen in (A). The data shown in (B) is an average of $n=10$ repeats.

Figure 3: Analytical ultracentrifugation analysis of the interaction of FliT with $\mathrm{FlhD}_{4} \mathrm{C}_{2}$. In the buffer conditions used FliT alone (grey solid line) behaves as a dimer with a molecular 
weight of $28 \mathrm{kDa}$ while the $\mathrm{FlhD}_{4} \mathrm{C}_{2}$ complex (black solid line) was calculated to have a mass of $94.9 \mathrm{kDa}$ in agreement with the published crystal structure (Wang et al., 2006). Addition of FliT to $\mathrm{FlhD}_{4} \mathrm{C}_{2}$ in a 1:1 ratio (black short dashed line) significantly reduced the $\mathrm{FlhD}_{4} \mathrm{C}_{2}$ peak. Surprisingly no new species of greater mass was identified. Instead a shoulder to the left of the $\mathrm{FlhD}_{4} \mathrm{C}_{2}$ peak was observed. When using greater $\mathrm{FliT}: \mathrm{FlhD}_{4} \mathrm{C}_{2}$ ratios at 5:1 (black long dashed line) or 10:1 (grey intermittent dashed line) this shoulder developed into an individual peak with a calculated mass of $61-63 \mathrm{kDa}$.

Figure 4: SPR analysis of FliT regulation of the $\mathrm{FlhD}_{4} \mathrm{C}_{2}$ :DNA interaction. (A) Concentration dependent binding of $\mathrm{FlhD}_{4} \mathrm{C}_{2}$ to $\mathrm{P}_{\text {flgB }}$ (black lines, solid symbols) and the inhibition of the interaction with 1:1 molar ratios of FliT (grey lines, open symbols). Circles: $200 \mathrm{nM}$; squares: $100 \mathrm{nM}$ and triangles: $50 \mathrm{nM}$. A buffer control (diamonds) is also included. (B) Analysis of the amount of FliT required to inhibit $\mathrm{FlhD}_{4} \mathrm{C}_{2}: \mathrm{P}_{\text {flgB }}$ DNA complex formation. All assays were performed using $100 \mathrm{nM} \mathrm{FlhD}{ }_{4} \mathrm{C}_{2}$. Circles: No FliT; squares: 100 nM FliT; triangles: 150 nM FliT; diamonds: 250 nM FliT; inverted triangles: 400 nM FliT. A buffer control (grey line) is also included. No further change was observed for concentrations higher than $400 \mathrm{nM}$ FliT (data not shown).

Figure 5: $A \mathrm{FlhD}_{4} \mathrm{C}_{2}$ :DNA complex is insensitive to FliT. (A) SPR profile of injection of buffer (grey dashes) or $100 \mathrm{nM} \mathrm{FliT} \mathrm{(black)} \mathrm{over} \mathrm{FlhD}_{4} \mathrm{C}_{2}: \mathrm{P}_{\text {flgB }}$ DNA complex. A similar result with the other DNA species and higher FliT concentrations was observed (data not shown). The arrows indicate the injection start time and stop time. The binding of $\mathrm{FlhD}_{4} \mathrm{C}_{2}$ to the DNA is not shown for clarity. (B) Unlabelled $\mathrm{P}_{f l g B}$ DNA is able to compete for bound $\mathrm{FlhD}_{4} \mathrm{C}_{2}$. SPR profiles showing the effect of injecting $100 \mathrm{nM} \mathrm{P} \mathrm{P}_{f l g B}$ unlabelled DNA over $\mathrm{FlhD}_{4} \mathrm{C}_{2}$ bound to $\mathrm{P}_{f l g B}$ (solid line), $\mathrm{P}_{f \mid h B}$ (short dashed line) and an intergenic region of fliC (long dashes). 
Figure 6: FliD acts as an anti-anti-FlhD $\mathrm{C}_{2}$ factor. SPR profiles of the influence of FliD on the ability of FliT to inhibit the $\mathrm{FlhD}_{4} \mathrm{C}_{2}: \mathrm{P}_{\text {flgB }}$ DNA interaction. In all experiments a $1: 1$ ratio of all components was used using a concentration of $100 \mathrm{nM}$. Circles: $\mathrm{FlhD}_{4} \mathrm{C}_{2}$ alone; triangles: $\mathrm{FlhD}_{4} \mathrm{C}_{2}+$ FliT; inverted triangles: $\mathrm{FlhD}_{4} \mathrm{C}_{2}+\mathrm{FliD}$; squares: $\mathrm{FlhD}_{4} \mathrm{C}_{2}+\mathrm{FliT}+\mathrm{FliD}$ and Gray Diamonds: Buffer control. Here resonance units are expressed relative to the maximal $\mathrm{RU}$ of $\mathrm{FlhD}_{4} \mathrm{C}_{2}$ alone.

Figure 7: Autoregulation of $\mathrm{P}_{\text {class } 1}\left(\mathrm{P}_{\text {flhDC }}\right)$ by $\mathrm{FlhD}_{4} \mathrm{C}_{2}$ responds to FliT inhibition of $\mathrm{FlhD}_{4} \mathrm{C}_{2} . \mathrm{P}_{f / h D C}$ activity was monitored over time in a growing culture. The change in $\mathrm{P}_{f h D C}$ activity in the $\Delta f l i T$ mutant compared to wild type was used in the genetic screen for fliT mutations. Wild type: circles; $\Delta$ fliT: diamonds; $\triangle$ fliD: squares; and $\triangle f l h D C$ : triangles. Deletion of $\Delta$ fliD did not show such a strong change in $\mathrm{P}_{\text {flhDC }}$ activity, as did deletion of fliT or $f / h D C$. Activity was calculated relative to optical density as described in Materials and Methods.

Figure 8: The interaction interface of FliT for FliD and $\mathrm{FlhD}_{4} \mathrm{C}_{2}$ overlap. (A) Motility assays using semi-solid agar of SJW1103 expressing gst-fliT94 with a series of alanine substitutions in $\alpha 3$ of FliT from the plasmid pGEX6p-1. (B) Immunoblot analysis using polyclonal anti-FIhC antibody of a GST-pull down assay of GST-FliT94 and its variants when expressed in S. enterica. The efficiency of isolating FlhC using E75A is significantly reduced (Imada et al., 2010). (C) SPR analysis of fliT94 compared to alleles containing N74A, E75A, K79A and L82A amino acid substitutions. $\mathrm{FlhD}_{4} \mathrm{C}_{2}$ alone and $\mathrm{FlhD}_{4} \mathrm{C}_{2}$ with FliT94 are shown as black lines in each data set for comparison. Each mutant is shown as

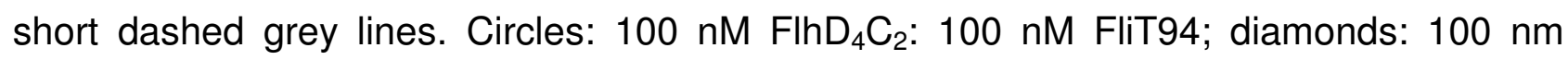
FlhD ${ }_{4} \mathrm{C}_{2}$ : 200 nM FliT94; triangles: $100 \mathrm{nM} \mathrm{FlhD}{ }_{4} \mathrm{C}_{2}$ : 400 nM FliT94; squares: buffer 
control, the same symbols are used for the same molar ratios of the alanine substitutions tested. Consistent with the motility data in (A), E75A showed the weakest ability to inhibit $\mathrm{FlhD}_{4} \mathrm{C}_{2}$ to interact with $\mathrm{P}_{f l g B}$ DNA. 


\section{References}

Adler, J. and Templeton B. (1967) The effect of environmental conditions on the motility of Escherichia coli. J Gen Microbiol 46: 175-184.

Aldridge, P., Karlinsey J. and Hughes K. T. (2003) The type III secretion chaperone FlgN regulates flagellar assembly via a negative feedback loop containing its chaperone substrates FlgK and FlgL. Mol Microbiol 49: 1333-1345.

Aldridge, P., Karlinsey J. E., Becker E., Chevance F. F. and Hughes K. T. (2006a) Flk prevents premature secretion of the anti-sigma factor FlgM into the periplasm. Mol Microbiol 60: 630-643.

Aldridge, P. D., Karlinsey J. E., Aldridge C., Birchall C., Thompson D., Yagasaki J. and Hughes K. T. (2006b) The flagellar-specific transcription factor, $\sigma^{28}$, is the Type III secretion chaperone for the flagellar-specific anti- $\sigma^{28}$ factor FlgM. Genes Dev 20: 2315-2326.

Bange, G., Kummerer N., Engel C., Bozkurt G., Wild K. and Sinning I. (2010) FlhA provides the adaptor for coordinated delivery of late flagella building blocks to the type III secretion system. Proc Natl Acad Sci U S A 107: 11295-11300.

Barkai, N. and Leibler S. (1997) Robustness in simple biochemical networks. Nature 387: 913-917.

Bonifield, H. R., Yamaguchi S. and Hughes K. T. (2000) The flagellar hook protein, FlgE, of Salmonella enterica serovar Typhimurium is posttranscriptionally regulated in response to the stage of flagellar assembly. J Bacteriol 182: 4044-4050.

Brown, J. D., Saini S., Aldridge C., Herbert J., Rao C. V. and Aldridge P. D. (2008) The rate of protein secretion dictates the temporal dynamics of flagellar gene expression. Mol Microbiol 70: 924-937. 
Chilcott, G. S. and Hughes K. T. (2000) Coupling of Flagellar Gene Expression to Flagellar Assembly in Salmonella enterica Serovar Typhimurium and Escherichia coli. Microbiol Mol Biol Rev.

Claret, L. and Hughes C. (2000) Functions of the subunits in the $\operatorname{FlhD}(2) \mathrm{C}(2)$ transcriptional master regulator of bacterial flagellum biogenesis and swarming. $J$ Mol Biol 303: 467-478.

Darnton, N., Turner L., Rojevsky S. and Berg H. C. (2007) On torque and tumbling in swimming Escherichia coli. J Bacteriol 189: 1756-1764.

Datsenko, K. A. and Wanner B. L. (2000) One-step inactivation of chromosomal genes in Escherichia coli K-12 using PCR products. Proc Natl Acad Sci U S A 97: 66406645.

Davis, R. W., Botstein D., Roth J. R. and Cold Spring Harbor N.Y. Laboratory of Quantitative Biology (1980) Advanced bacterial genetics: a manual for genetic engineering. Cold Spring Harbor Laboratory, Cold Spring Harbor, N.Y.

Erhardt, M. and Hughes K. T. (2010) C-ring requirement in flagellar type III secretion is bypassed by FlhDC upregulation. Mol Microbio/ 75: 376-393.

Evans, L. D., Stafford G. P., Ahmed S., Fraser G. M. and Hughes C. (2006) An escort mechanism for cycling of export chaperones during flagellum assembly. Proc Natl Acad Sci U S A 103: 17474-17479.

Fraser, G. M., Bennett J. C. and Hughes C. (1999) Substrate-specific binding of hookassociated proteins by FlgN and FliT, putative chaperones for flagellum assembly. Mol Microbio/ 32: 569-580.

Gillen, K. L. and Hughes K. T. (1991a) Molecular characterization of flgM, a gene encoding a negative regulator of flagellin synthesis in Salmonella typhimurium. $J$ Bacteriol 173: 6453-6459. 
Gillen, K. L. and Hughes K. T. (1991b) Negative regulatory loci coupling flagellin synthesis to flagellar assembly in Salmonella typhimurium. J Bacteriol 173: 2301-2310.

Goodier, R. I. and Ahmer B. M. (2001) SirA orthologs affect both motility and virulence. J Bacteriol 183: 2249-2258.

Hughes, K. T., Gillen K. L., Semon M. J. and Karlinsey J. E. (1993) Sensing structural intermediates in bacterial flagellar assembly by export of a negative regulator. Science 262: 1277-1280.

lino, T. (1974) Assembly of Salmonella flagellin in vitro and in vivo. J Supramol Struct 2: 372-384.

Imada, K., Minamino T., Kinoshita M., Furukawa Y. and Namba K. (2010) Structural insight into the regulatory mechanisms of interactions of the flagellar type III chaperone FliT with its binding partners. Proc Natl Acad Sci U S A.

Karlinsey, J. E., Tanaka S., Bettenworth V., Yamaguchi S., Boos W., Aizawa S. I. and Hughes K. T. (2000) Completion of the hook-basal body complex of the Salmonella typhimurium flagellum is coupled to FlgM secretion and fliC transcription. Mol Microbio/ 37: 1220-1231.

Kutsukake, K. and lino T. (1994) Role of the FliA-FlgM regulatory system on the transcriptional control of the flagellar regulon and flagellar formation in Salmonella typhimurium. J Bacteriol 176: 3598-3605.

Kutsukake, K., Ikebe T. and Yamamoto S. (1999) Two novel regulatory genes, fliT and fliZ, in the flagellar regulon of Salmonella. Genes Genet Syst 74: 287-292.

Liu, X., Fujita N., Ishihama A. and Matsumura P. (1995) The C-terminal region of the alpha subunit of Escherichia coli RNA polymerase is required for transcriptional activation of the flagellar level II operons by the FlhD/FlhC complex. J Bacteriol 177: 51865188. 
Murray, H. and Errington J. (2008) Dynamic control of the DNA replication initiation protein DnaA by Soj/ParA. Cell 135: 74-84.

Ohnishi, K., Kutsukake K., Suzuki H. and lino T. (1990) Gene fliA encodes an alternative sigma factor specific for flagellar operons in Salmonella typhimurium. Mol Gen Genet 221: 139-147.

Overgaard, M., Borch J., Jorgensen M. G. and Gerdes K. (2008) Messenger RNA interferase RelE controls relBE transcription by conditional cooperativity. Mol Microbiol 69: 841-857.

Pruss, B. M. and Matsumura P. (1996) A regulator of the flagellar regulon of Escherichia coli, flhD, also affects cell division. J Bacteriol 178: 668-674.

Pruss, B. M. and Matsumura P. (1997) Cell cycle regulation of flagellar genes. J Bacteriol 179: $5602-5604$.

Saijo-Hamano, Y., Imada K., Minamino T., Kihara M., Shimada M., Kitao A. and Namba K. (2010) Structure of the cytoplasmic domain of FlhA and implication for flagellar type III protein export. Mol Microbiol 76: 260-268.

Saini, S., Brown J. D., Aldridge P. D. and Rao C. V. (2008) FliZ Is a posttranslational activator of $\mathrm{FlhD}_{4} \mathrm{C}_{2}$-dependent flagellar gene expression. $J$ Bacteriol 190: 49794988.

Schaechter, M., Maaloe O. and Kjeldgaard N. O. (1958) Dependency on medium and temperature of cell size and chemical composition during balanced grown of Salmonella typhimurium. J Gen Microbiol 19: 592-606.

Schuck, P. (1998) Sedimentation analysis of noninteracting and self-associating solutes using numerical solutions to the Lamm equation. Biophys J 75: 1503-1512.

Schuck, P. (2003) On the analysis of protein self-association by sedimentation velocity analytical ultracentrifugation. Anal Biochem 320: 104-124. 
Soutourina, O. A. and Bertin P. N. (2003) Regulation cascade of flagellar expression in Gram-negative bacteria. FEMS Microbiol Rev 27: 505-523.

Stafford, G. P., Ogi T. and Hughes C. (2005) Binding and transcriptional activation of nonflagellar genes by the Escherichia coli flagellar master regulator $\mathrm{FlhD}_{2} \mathrm{C}_{2}$. Microbiology 151: 1779-1788.

Turner, L., Ryu W. S. and Berg H. C. (2000) Real-time imaging of fluorescent flagellar filaments. J Bacteriol 182: 2793-2801.

Vogel, H. J. and Bonner D. M. (1956) Acetylornithinase of Escherichia coli: partial purification and some properties. J Biol Chem 218: 97-106.

Wang, S., Fleming R. T., Westbrook E. M., Matsumura P. and McKay D. B. (2006) Structure of the Escherichia coli FlhDC complex, a prokaryotic heteromeric regulator of transcription. J Mol Bio/ 355: 798-808.

Yamamoto, S. and Kutsukake K. (2006) FliT acts as an anti-FlhD $\mathrm{C}_{2}$ factor in the transcriptional control of the flagellar regulon in Salmonella enterica serovar Typhimurium. J Bacteriol 188: 6703-6708. 
Figure 1
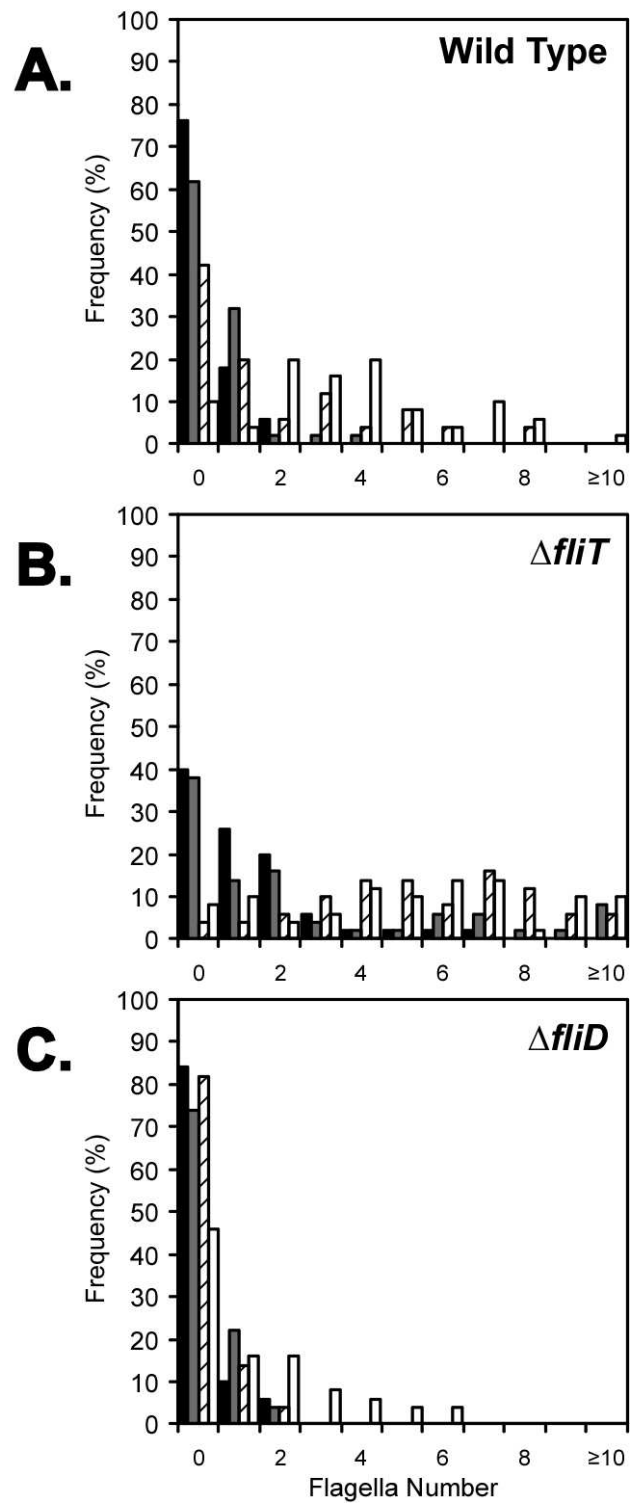

$128 \times 274 \mathrm{~mm}(150 \times 150 \mathrm{DPI})$ 


\section{Figure 2}

A.
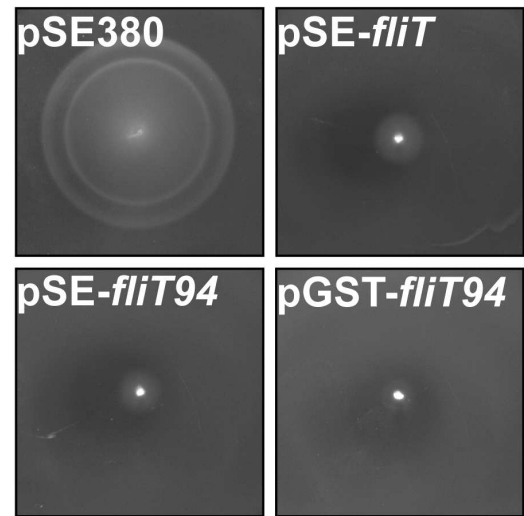

pSE-flgM

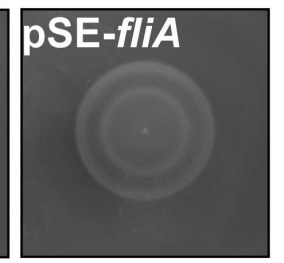

B.

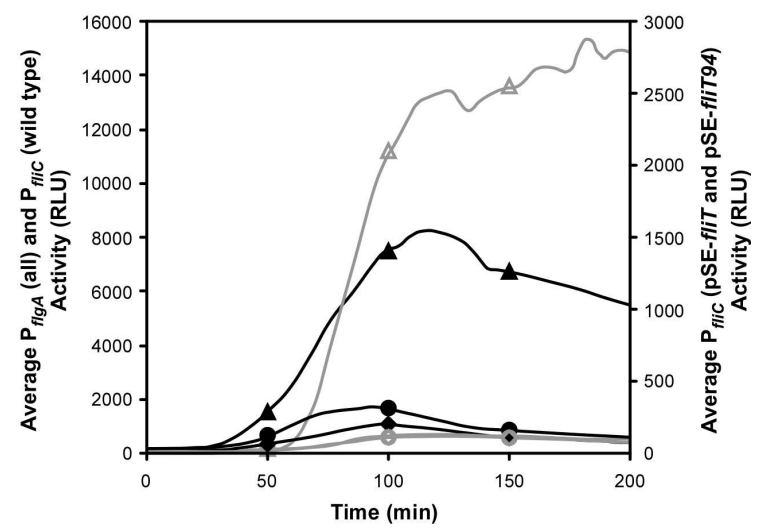

$130 \times 230 \mathrm{~mm}(300 \times 300 \mathrm{DPI})$ 
Figure 3

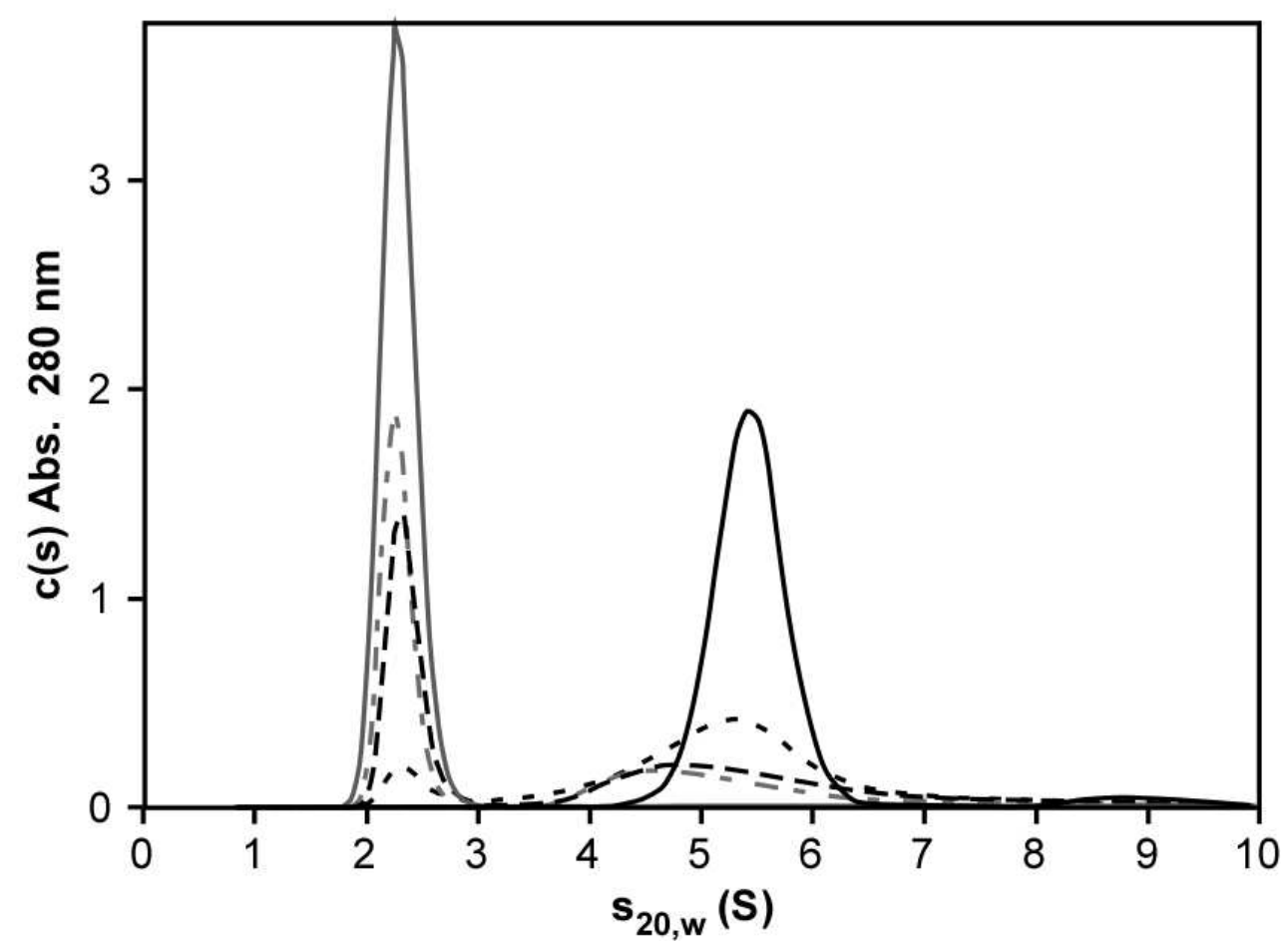

$147 \times 123 \mathrm{~mm}(150 \times 150 \mathrm{DPI})$ 
Figure 4

A.

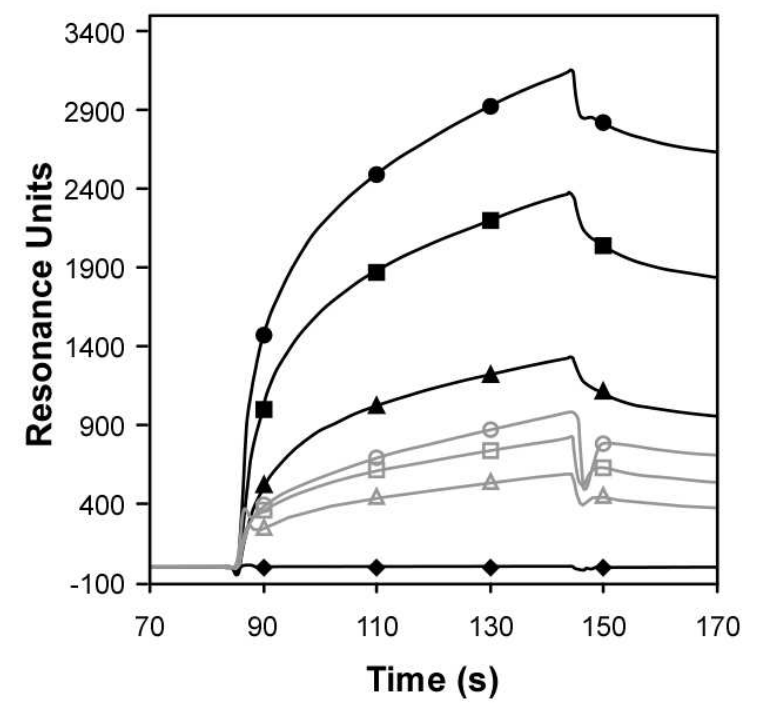

B.

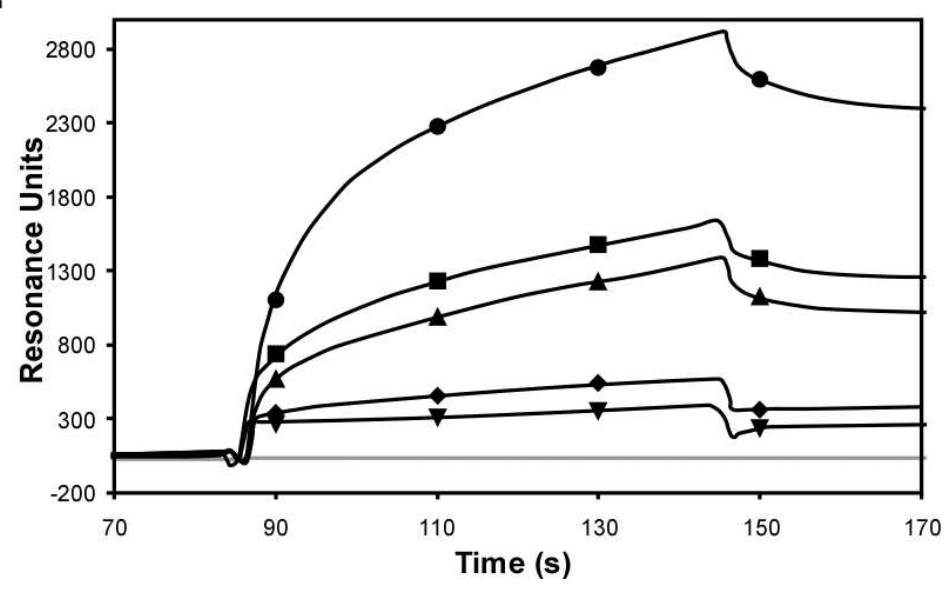

$143 \times 224 \mathrm{~mm}(150 \times 150 \mathrm{DPI})$ 


\section{Figure 5}
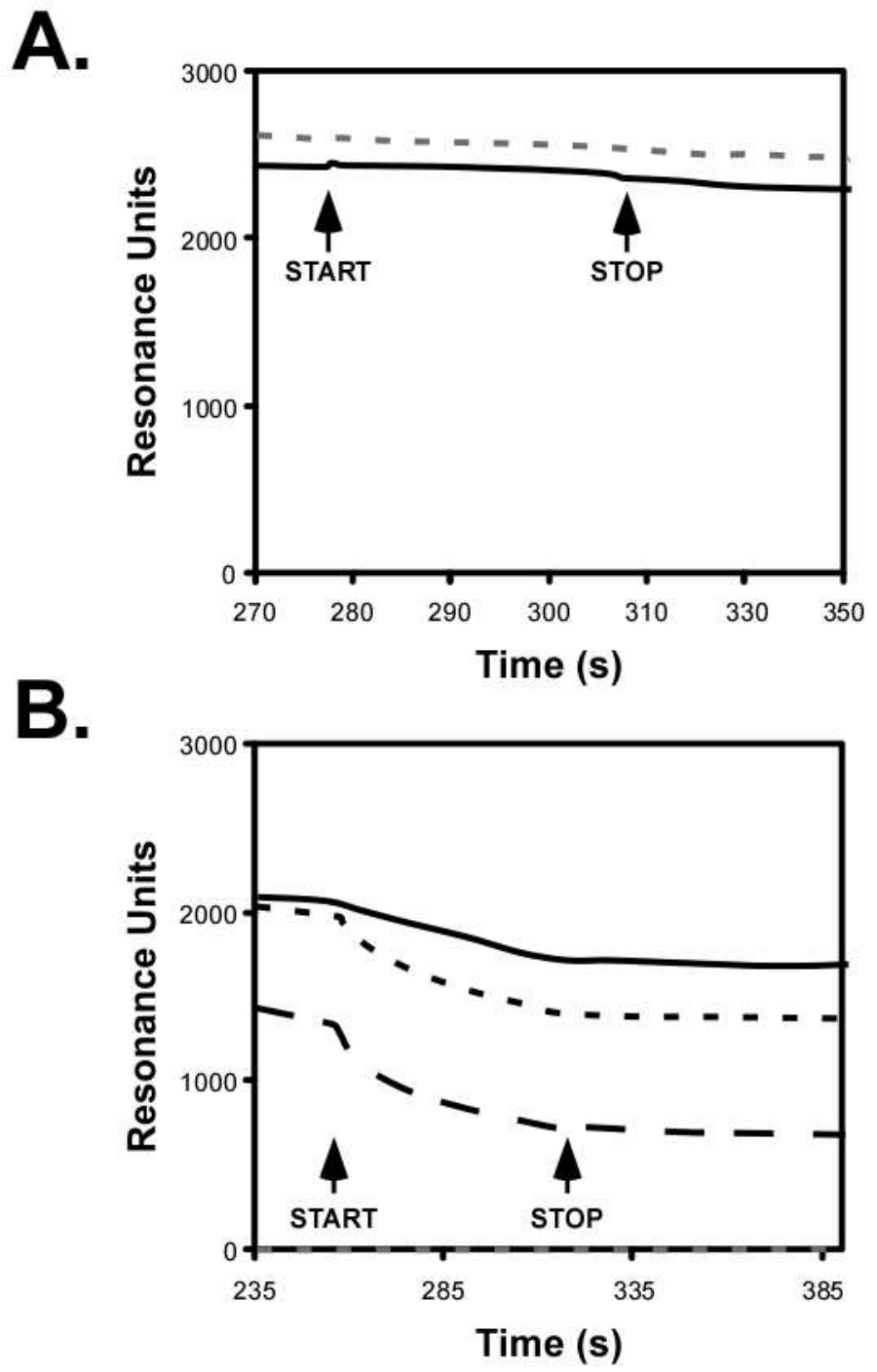

$107 \times 158 \mathrm{~mm}(150 \times 150 \mathrm{DPI})$ 
Figure 6

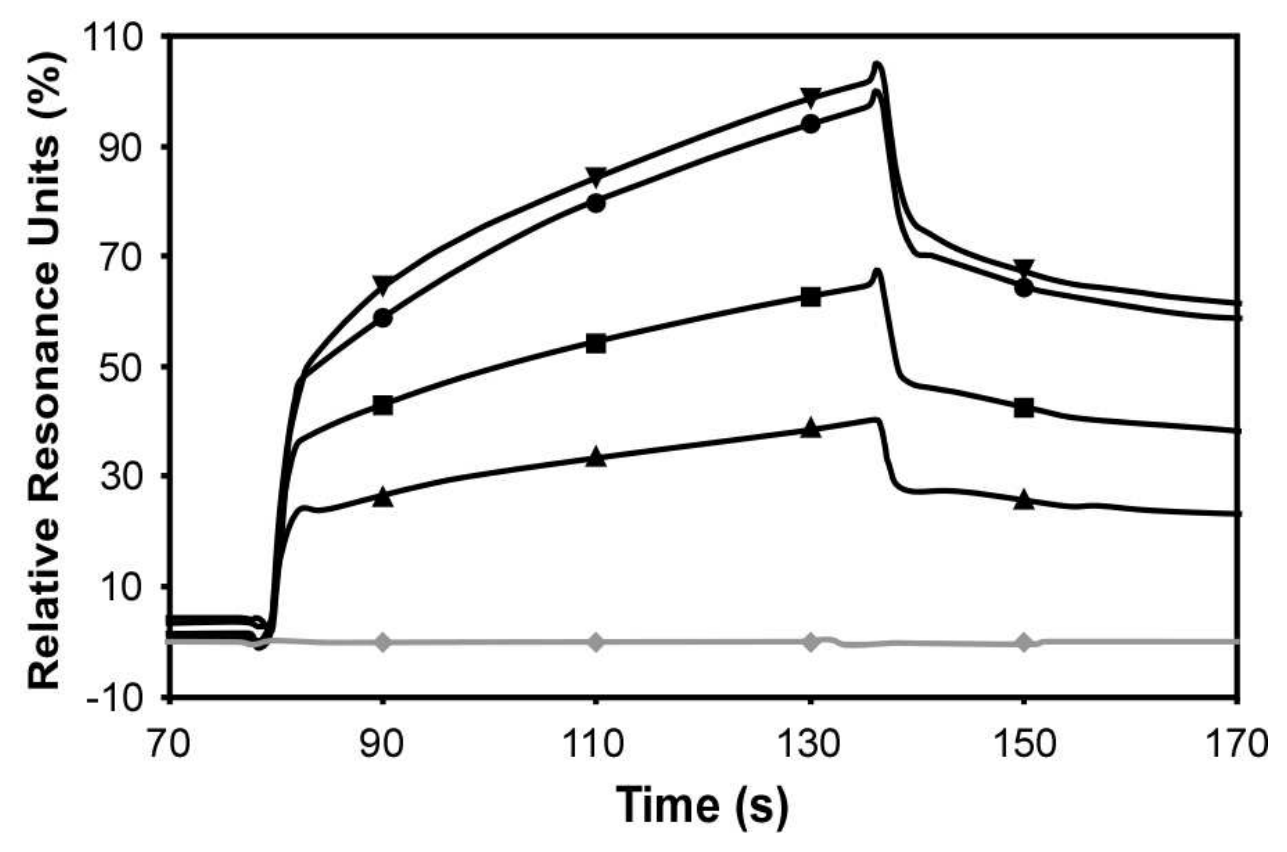

$159 \times 123 \mathrm{~mm}(150 \times 150 \mathrm{DPI})$ 
Figure 7

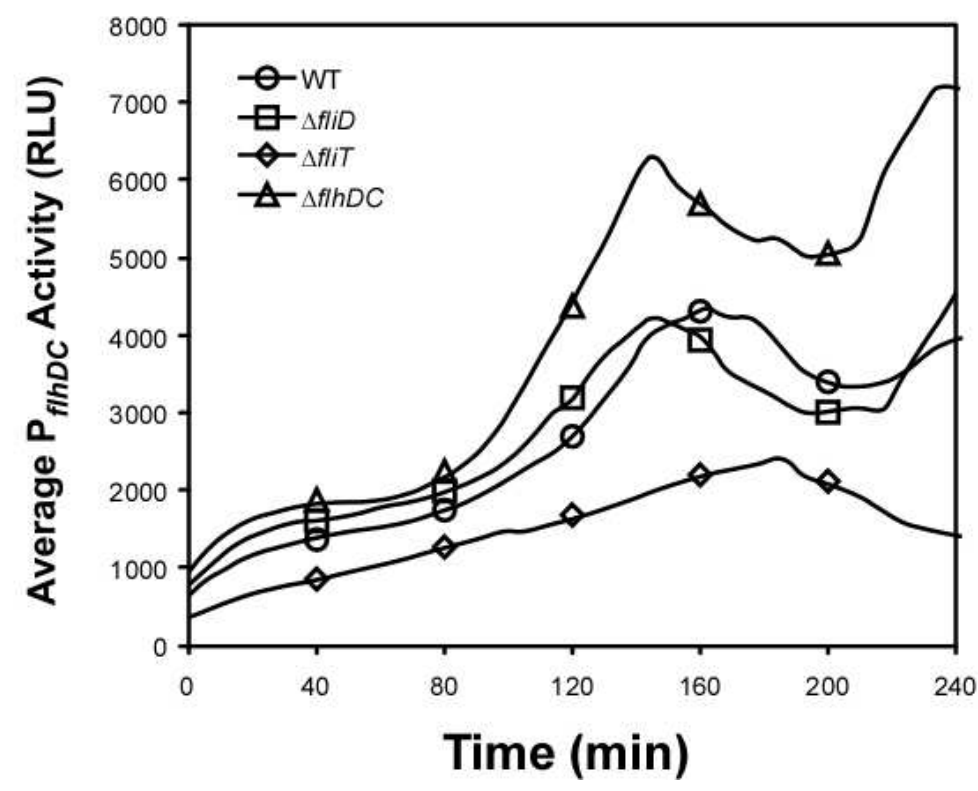

$125 \times 93 \mathrm{~mm}(150 \times 150 \mathrm{DPI})$ 


\section{Figure 8}

A

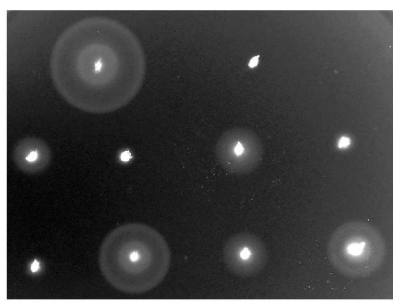

GST GST-FliT94

GST-FliT94 GST-FliT94 GST-FliT94 GST-FliT94 $\begin{array}{llll}(\text { I68A) } & (\text { L72A) } & \text { (N74A) } & \text { (L81A) }\end{array}$

GST-FliT94 GST-FliT94 GST-FliT94 GST-FliT94 $\begin{array}{llll}(\mathrm{Q} 83 \mathrm{~A}) & (\mathrm{E} 75 \mathrm{~A}) & (\mathrm{K} 79 \mathrm{~A}) & (\mathrm{L} 82 \mathrm{~A})\end{array}$
B
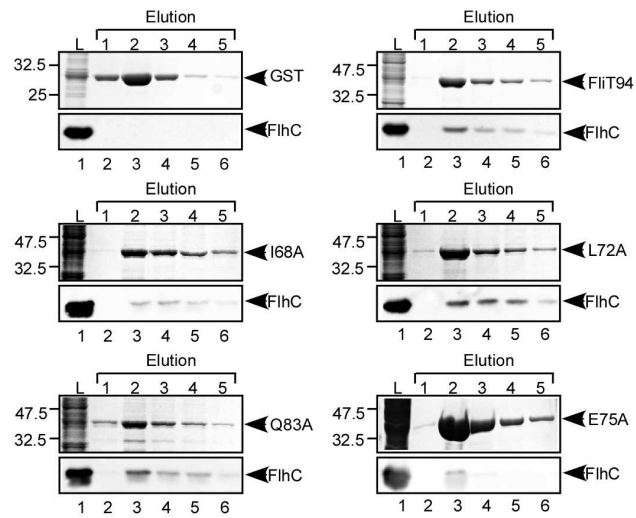

C
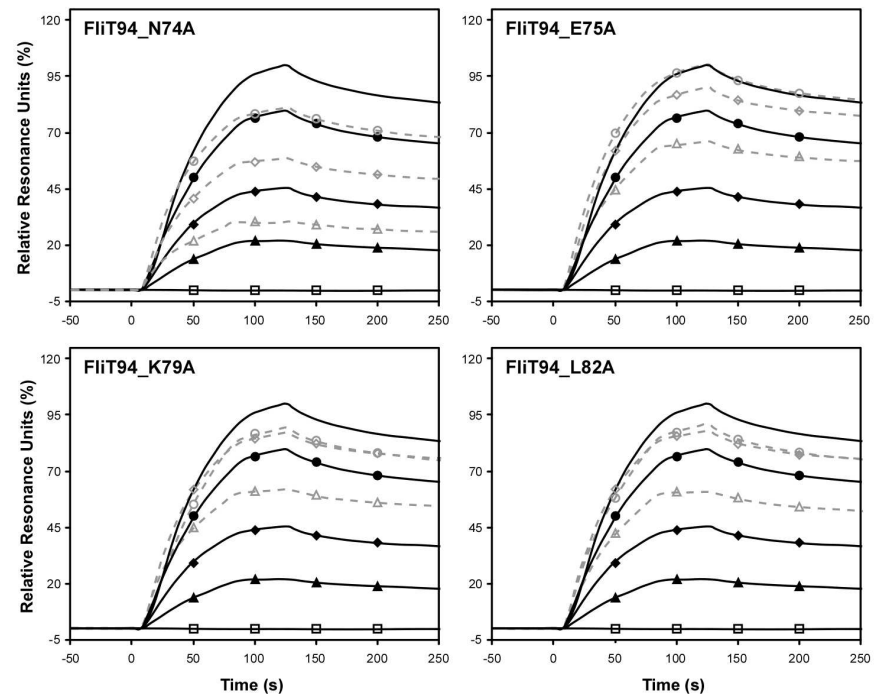

$186 \times 218 \mathrm{~mm}(300 \times 300$ DPI $)$ 